\title{
Alkoxy hydrosilanes as surrogates of gaseous silanes for hydrosilylation of alkenes
}

Ivan Buslov, Sébastien Carlos Keller and Xile Hu*

Laboratory of Inorganic Synthesis and Catalysis

Institute of Chemical Sciences and Engineering

Ecole Polytechnique Fédérale de Lausanne (EPFL)

ISIC-LSCI, BCH 3305, Lausanne 1015 (Switzerland)

E-mail: xile.hu@epfl.ch

\section{Supporting information}

\begin{tabular}{|l|c|}
\hline \multicolumn{1}{|c|}{ Content } & Page \\
\hline $\begin{array}{l}\text { 1. Chemicals and Reagents } \\
\text { 2. Physical methods }\end{array}$ & S2 \\
\hline 3. The procedures for the preparation of starting materials & S3 \\
\hline 4. General procedures for the hydrosilylation reactions & S4 \\
\hline 5.NMR experiments & S6 \\
\hline 6. Detailed descriptions of the products & S18 \\
\hline 7. Limitations & S29 \\
\hline 7. References & S30 \\
\hline 8. NMR spectra & S31 \\
\hline
\end{tabular}




\section{Chemicals and Reagents}

All manipulations were carried out under an inert $\mathrm{N}_{2}(\mathrm{~g})$ atmosphere using standard Schlenk or glovebox techniques. Solvents were purified using a two-column solid-state purification system (Innovative Technology, NJ, USA) and transferred to the glove box without exposure to air. Deuterated solvents were purchased from Cambridge Isotope Laboratories, Inc., and were degassed and stored over activated $3 \AA$ molecular sieves. THF- $\mathrm{d}_{8}$ was purchased from ARMAR AG, and was degassed and stored over activated $3 \AA$ molecular sieves. Unless otherwise noted, all other reagents and starting materials were purchased from commercial sources and used without further purification. Liquid compounds were degassed by standard freeze-pump-thaw procedures prior to use. The following chemicals were prepared according to procedures in the literature:

substrates 6-(benzyloxy)-hex-1-ene (3f) ${ }^{1}$, tert-butyl(hex-5-enyloxy)dimethylsilane $(\mathbf{3 h})^{2}$, 6(2-tetrahydropyranyl)oxy-l-hexene (3i) ${ }^{3}$, 2,2-dimethyl-4-pentenal ethylene acetal (3i) ${ }^{4}$; complexes $1 \mathbf{a}^{5}$ and $\mathbf{1} \mathbf{b}^{6}, \mathbf{1} \mathbf{c}^{7}$ and $\mathbf{1} \mathbf{d}^{8}$.

\section{Physical methods}

The ${ }^{1} \mathrm{H}$ and ${ }^{13} \mathrm{C}$ NMR spectra were recorded at $293 \mathrm{~K}$ or $373 \mathrm{~K}$ on Bruker Avance 400 spectrometers. ${ }^{1} \mathrm{H}$ NMR chemical shifts were referenced to residual solvent as determined relative to $\mathrm{Me}_{4} \mathrm{Si}(\delta=0 \mathrm{ppm})$. The ${ }^{13} \mathrm{C}\left\{{ }^{1} \mathrm{H}\right\}$ chemical shifts were reported in ppm relative to the carbon resonance of $\mathrm{CDCl}_{3}$ (77.16 ppm), $\mathrm{C}_{6} \mathrm{D}_{6}$ (128.06). GC measurement was conducted on a Perkin-Elmer Clarus 400 GC with a FID detector. GC-MS measurements were conducted on an Agilent Technologies 7890A GC system equipped with a 5975C MS detector. HRMS (ESI, APCI and APPI) measurements were conducted at the EPFL ISIC Mass Spectrometry Service with a Micro Mass QTOF. Elemental analyses were performed on a Carlo Erba EA 1110 CHN instrument at EPFL. 


\section{The procedures for the preparation of starting materials}

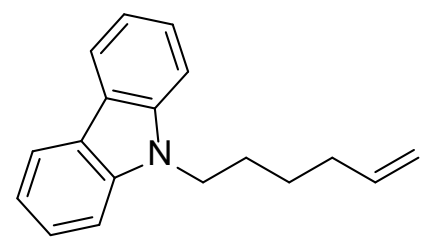

\section{9-(hex-5-en-1-yl)-9H-carbazole (3k)}

A $100 \mathrm{~mL}$ round-bottom flask equipped with a Teflon-coated magnetic stirring bar was charged with 9H-carbazole (1.0 g, $6.0 \mathrm{mmol})$ and $15 \mathrm{~mL}$ of DMF. Sodium hydride (240 mg of 60 percent suspension in mineral oil, $6.0 \mathrm{mmol}$ ) was added and the reaction stirred at room temperature for $1 \mathrm{~h}$. 6-bromohex-1-ene (1.47 $\mathrm{g}, 9.0 \mathrm{mmol})$ was added and the reaction allowed to stir for an additional $2 \mathrm{~h}$ at $80^{\circ} \mathrm{C}$. Water was added and the mixture extracted with $\mathrm{CH}_{2} \mathrm{Cl}_{2}$. The organic layer was dried with anhydrous $\mathrm{Na}_{2} \mathrm{SO}_{4}$ and concentrated in vacuo. The crude product was purified by flash chromatography with silica gel using a mixture of hexane/EtOAc (20:1) as an eluent to afford the title compound (3k) as a pale-yellow solid (1.34 g, $89 \%)$.

${ }^{1}$ H NMR (400 MHz, $\left.\mathrm{CDCl}_{3}\right) \delta$ 8.10-8.08 (m, 2H), 7.46-7.36 (m, 4H), 7.23-7.20 (m, 2H), 5.78-5.68 (m, 1H), 4.99-4.91 (m, 2H), 4.27 (t, $J=7.1 \mathrm{~Hz}, 2 \mathrm{H}), 2.08-2.04$ (m, 2H), 1.87-1.82 (m, 2H), 1.50-1.43 (m, 2H).

${ }^{13}$ C NMR $\left(101 \mathrm{MHz}, \mathrm{CDCl}_{3}\right) \delta 140.5,138.4,125.7,123.0,120.5,118.9,115.1,108.8,43.0$, 33.6, 28.5, 26.7.

HRMS (ESI): calculated for $\left(\mathrm{C}_{18} \mathrm{H}_{20} \mathrm{~N},[\mathrm{M}+\mathrm{H}]^{+}\right)$, 250.1596; found 250.1595. 


\section{General procedures for hydrosilylation reactions}

Safety note: The reactions involve $\mathrm{Me}_{2} \mathrm{SiH}_{2}, \mathrm{MeSiH}_{3}$ and $\mathrm{SiH}_{4}$ as intermediates which are flammable gases. Although during catalysis $\mathrm{MeSiH}_{3}$ and $\mathrm{SiH}_{4}$ was not observed, and $\mathrm{Me}_{2} \mathrm{SiH}_{2}$ was only present in the beginning of the reaction, cautions should be made. The reactions run in closed vessels may be subjected to increased pressures, although this was not encountered in our experiments. The reaction vessels should be purged with $\mathrm{N}_{2}$ prior the contact with air.

\section{Preparation of the stock solution of pre-catalyst}

A stock solution of pre-catalyst was prepared by dissolving $120 \mathrm{mg}(0.25 \mathrm{mmol})$ of complex [iPr $-(\mathrm{S}, \mathrm{S})-\mathrm{BOZ}] \mathrm{NiCl}(\mathbf{1 a})$ and $48 \mathrm{mg}(0.5 \mathrm{mmol})$ of $\mathrm{NaO}^{\mathrm{t}} \mathrm{Bu}$ in $20.0 \mathrm{~mL}$ of dry THF.

\section{General procedure for the Ni-catalyzed hydrosilylation using 2 a and alkenes} (General Procedure I, Scheme 2)

In a nitrogen filled glovebox, an oven-dried $30 \mathrm{~mL}$ re-sealable screw-cap vial equipped with a Teflon coated magnetic stirring bar was charged with alkene (0.5 mmol), dimethylmethoxysilane (2a) $(1.2 \mathrm{mmol})$ and dry THF (2 $\mathrm{mL})$. An aliquot of the stock solution of complex $1 \mathrm{a}$ and $\mathrm{NaO}^{\mathrm{t}} \mathrm{Bu}(1.0 \mathrm{~mL}$, corresponding to $2.5 \mathrm{~mol} \%$ of Ni catalyst) was added and the resulting mixture was stirred at room temperature for indicated time. After that, the vial was opened in the glovebox, purged with $\mathrm{N}_{2}$, closed and removed from the glovebox. The reaction mixture was concentrated under vacuum. The residue was purified by flash chromatography to afford the desired product.

General procedure for the Ni-catalyzed synthesis of alkyl hydrosilanes using $2 \mathrm{~b}$ and alkenes.

\section{(General Procedure II, Scheme 3)}

In a nitrogen filled glovebox, an oven-dried $30 \mathrm{~mL}$ re-sealable screw-cap vial equipped with a Teflon coated magnetic stirring bar was charged with alkene (1.2 mmol), methyldiethoxysilane (2b) (1.5 mmol) and dry THF (2 mL). An aliquot of the stock solution of complex 1a and $\mathrm{NaOtBu}(2.0 \mathrm{~mL}$, corresponding to $5 \mathrm{~mol} \%$ of Ni catalyst) was added and the resulting mixture was stirred at room temperature for indicated time. After that, the vial 
was opened in the glovebox, purged with $\mathrm{N}_{2}$, closed and removed from the glovebox. The reaction mixture was concentrated under vacuum. The residue was purified by flash chromatography to afford the desired product.

General procedure for the Ni-catalyzed synthesis of alkyl hydrosilanes using $2 \mathrm{c}$ and alkenes.

\section{(General Procedure III, Scheme 3)}

In a nitrogen filled glovebox, an oven-dried $30 \mathrm{~mL}$ re-sealable screw-cap vial equipped with a Teflon coated magnetic stirring bar was charged with alkene (1.5 mmol), trimethoxysilane (2c) $(2 \mathrm{mmol})$ and dry THF (2 mL). An aliquot of the stock solution of complex $1 \mathbf{a}$ and $\mathrm{NaO}^{\mathrm{t}} \mathrm{Bu}(2.0 \mathrm{~mL}$, corresponding to $5 \mathrm{~mol} \%$ of $\mathrm{Ni}$ catalyst) was added and the resulting mixture was stirred at room temperature for indicated time. After that, the vial was opened in the glovebox, purged with $\mathrm{N}_{2}$, closed and removed from the glovebox. The reaction mixture was concentrated under vacuum. The residue was purified by flash chromatography to afford the desired product. 


\section{NMR experiments}

\section{Following the disproportionation of $2 \mathrm{a}$}

In a nitrogen filled glovebox, J. Young NMR tube was charged with $\mathrm{NaO}^{\mathrm{t}} \mathrm{Bu}(2.0 \mathrm{mg}, 21$ $\mu \mathrm{mol})$ and THF- $\mathrm{d}_{8}(0.3 \mathrm{~mL})$. To the solution dimethylmethoxysilane (2a) (23 mg, 0.25 mmol) in THF- $\mathrm{d}_{8}(0.3 \mathrm{~mL})$ was added. Outside the glovebox, the tube was shaken prior to introduction in to the NMR spectrometer. The ${ }^{1} \mathrm{H}$ spectrum was recorded after 3 min (Fig. S1), all following spectra were identical.

Ib3062_Me2MeOSiH_NaOtBu.1.fid $1 \mathrm{Hzg}$

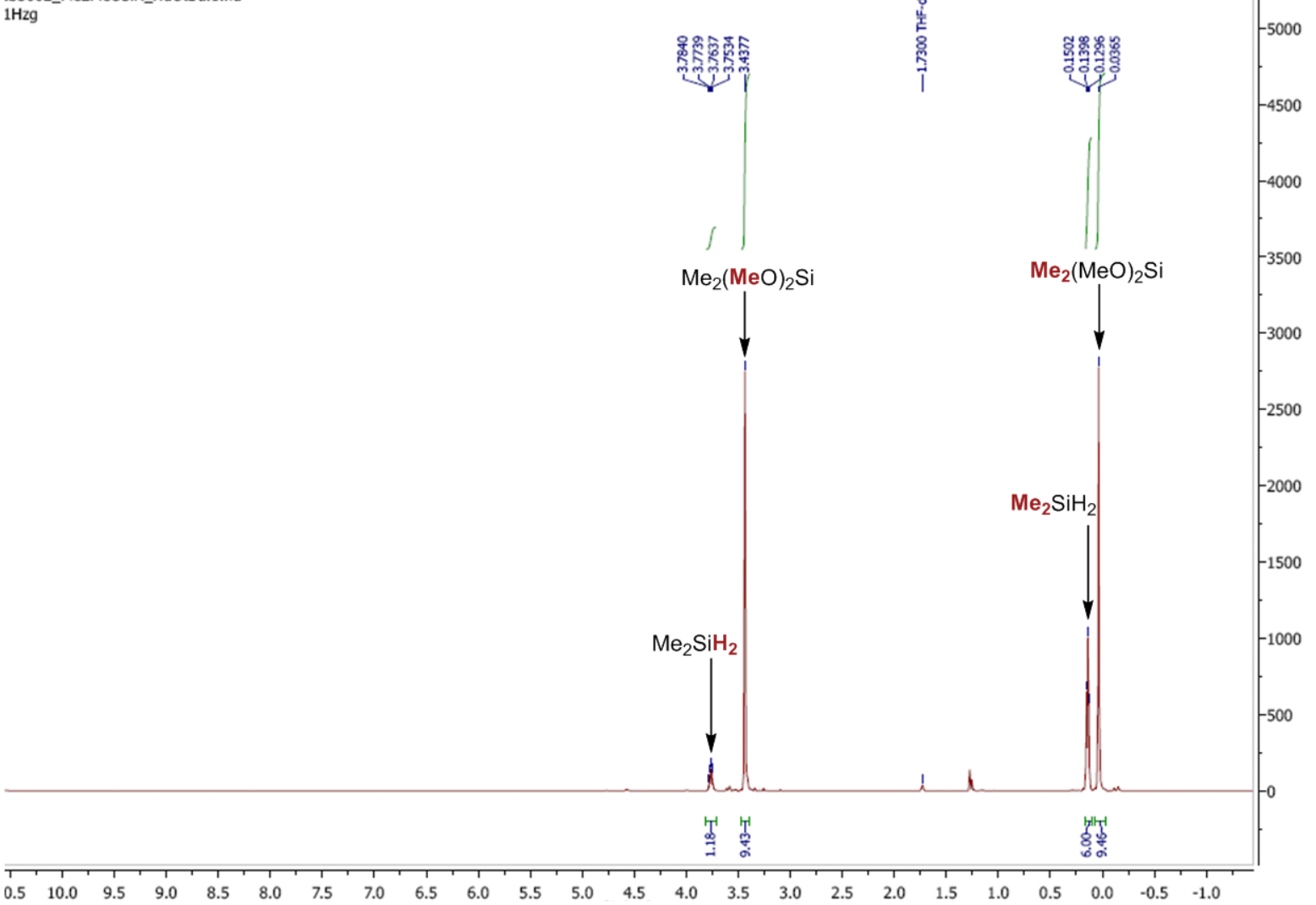

Fig. S1. $\mathrm{NaO}^{t} \mathrm{Bu}-$ catalyzed disproportionation of $2 \mathrm{a}$ 


\section{Monitoring of the reaction of Table 1, entry 1.}

In a nitrogen filled glovebox, an oven-dried vial was charged with 1-decene (3a) (42 mg, 0.3 mmol), dimethylmethoxysilane (2a) (45 mg, $0.5 \mathrm{mmol}$ ), mesitylene (9 mg, $0.075 \mathrm{mmol}$ ) and THF- $_{8}(0.6 \mathrm{~mL})$. The solution was placed in J. Young NMR tube and ${ }^{1} \mathrm{H}$ spectrum was recorded. Back in the glovebox a solution of complex $\mathbf{1 a}(3 \mathrm{mg}, 6 \mu \mathrm{mol})$ and $\mathrm{NaO}^{\mathrm{t}} \mathrm{Bu}(1.5$ $\mathrm{mg}, 15 \mu \mathrm{mol})$ in $0.4 \mathrm{~mL}$ of THF- $\mathrm{d}_{8}$ was added, the tube was closed and taken out. Outside the glovebox, the tube was shaken prior to introduction in to the NMR spectrometer. First measurement was made after 2 min from the moment when catalyst was added. (Fig. S2).

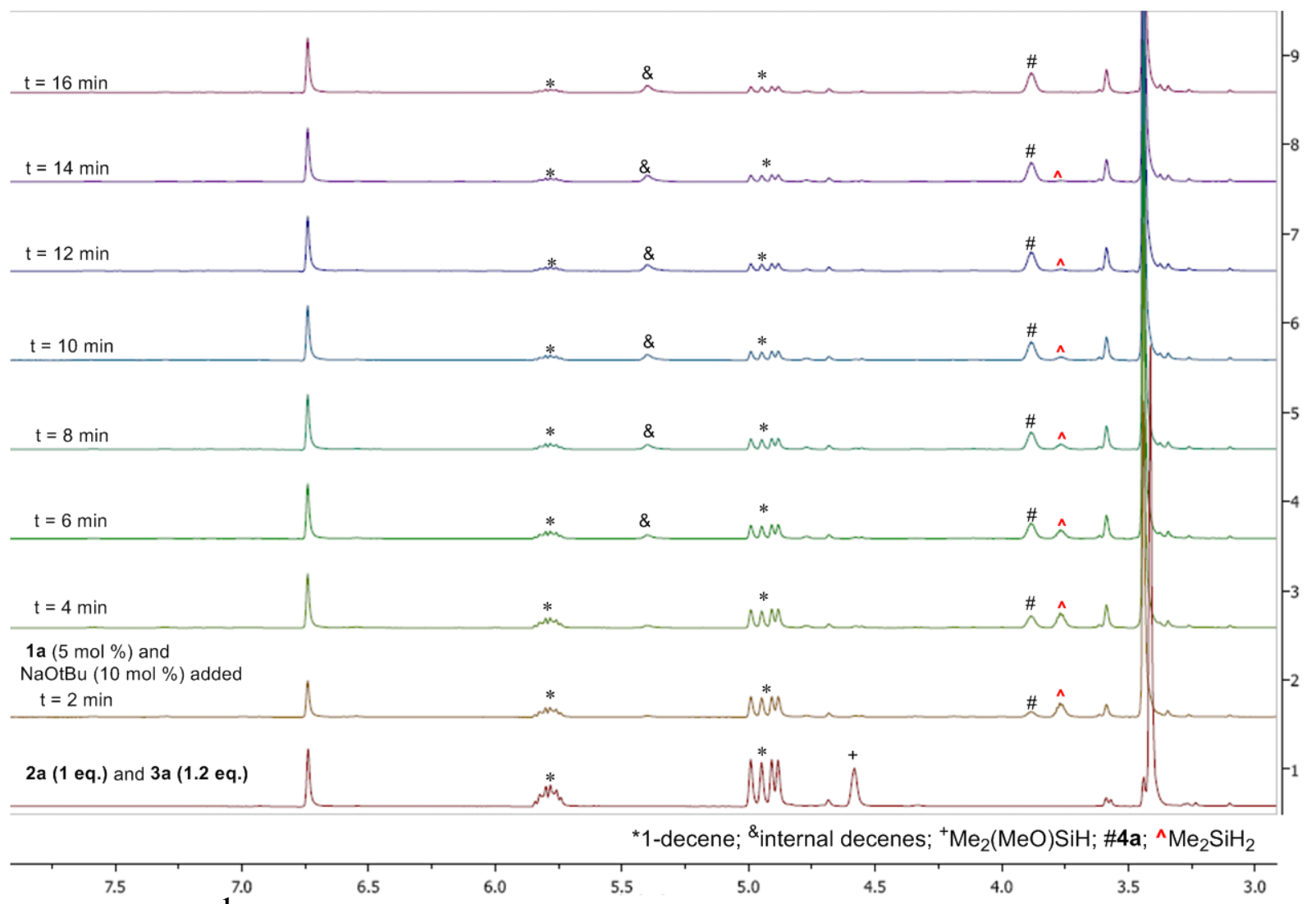

Fig. S2. Stack ${ }^{1}$ H NMR spectra (THF-d8) 


\section{Following disproportionation of 2c}

In a nitrogen filled glovebox, J. Young NMR tube was charged with $\mathrm{NaO}^{\mathrm{t}} \mathrm{Bu}(2.0 \mathrm{mg}, 21$ $\mu \mathrm{mol})$ and THF- $\mathrm{d}_{8}(0.3 \mathrm{~mL})$. To the solution trimethoxysilane (2c) (31 $\left.\mathrm{mg}, 0.25 \mathrm{mmol}\right)$ in THF- $_{8}(0.3 \mathrm{~mL})$ was added. Outside the glovebox, the tube was shaken prior to introduction in to the NMR spectrometer. The spectrum was recorded after 3 min (Fig. S3), all following spectra (5, 10, $15 \mathrm{~min})$ were almost identical.

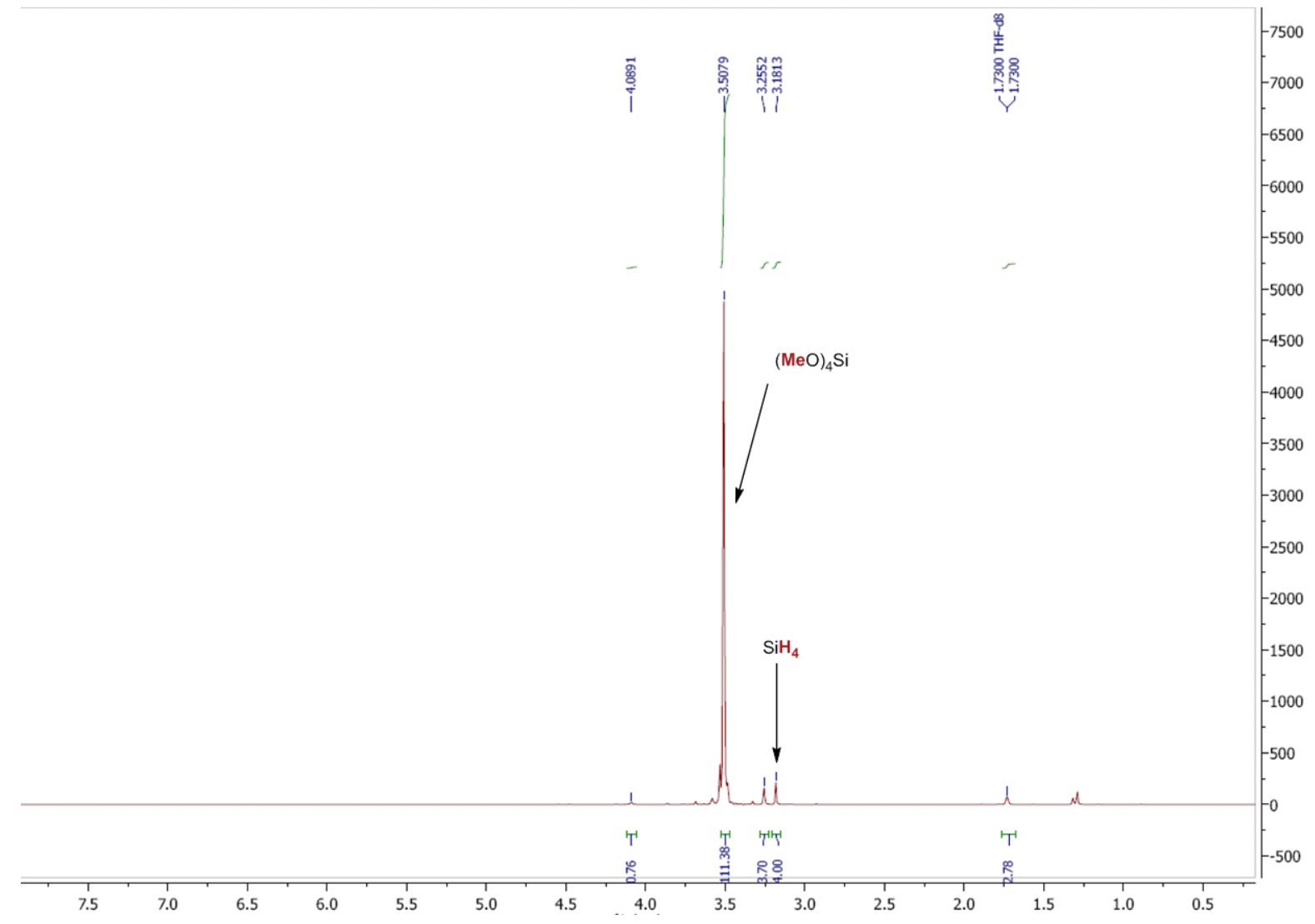

Fig. S3. $\mathrm{NaO}^{t} \mathrm{Bu}$ catalyzed disproportionation of $2 \mathrm{c}$ 
In order to prove that the peak at $3.18 \mathrm{ppm}$ corresponds to the protons of $\mathrm{SiH}_{4}$, a stream of $\mathrm{SiH}_{4}$ obtained in a separated vessel by disproportionation of neat $\mathbf{2} \mathbf{c}$ was bubbled through THF- $\mathrm{d}_{8}$ in NMR tube (Fig. S4)

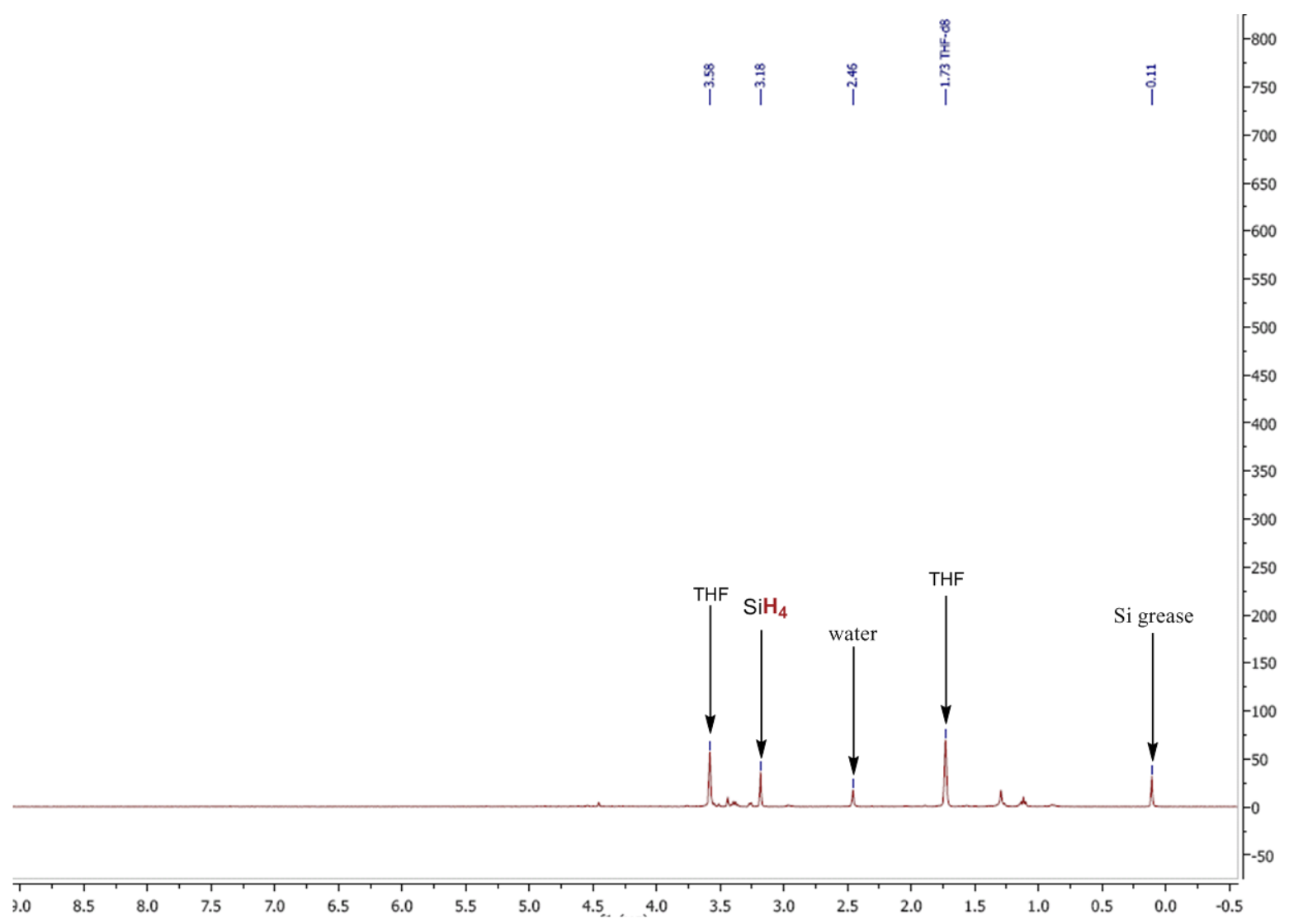

Fig. S4. $\mathrm{SiH}_{4}$ in THF-d 8 (3.18 ppm) 


\section{Monitoring of the reaction of 3a with 2c}

In a nitrogen filled glovebox, an oven-dried vial was charged with 1-decene (3a) (63 mg, 0.45 mmol), trimethoxysilane (2c) (61 mg, $0.5 \mathrm{mmol}$ ), mesitylene (10 mg, $0.083 \mathrm{mmol}$ ) and THF$\mathrm{d}_{8}(0.6 \mathrm{~mL})$. The solution was placed in J. Young NMR tube and a solution of complex 1a (3 $\mathrm{mg}, 6 \mu \mathrm{mol})$ and $\mathrm{NaO}^{\mathrm{t}} \mathrm{Bu}(1.5 \mathrm{mg}, 15 \mu \mathrm{mol})$ in $0.4 \mathrm{~mL}$ of THF-d $\mathrm{d}_{8}$ was added. The tube was immediately closed and taken out. Outside the glovebox, the tube was shaken prior to introduction in to the NMR spectrometer. First measurement was made after 4 min from the moment when catalyst was added. (Fig. S5). No peak of $\mathrm{SiH}_{4}$ was observed in the course of reaction.

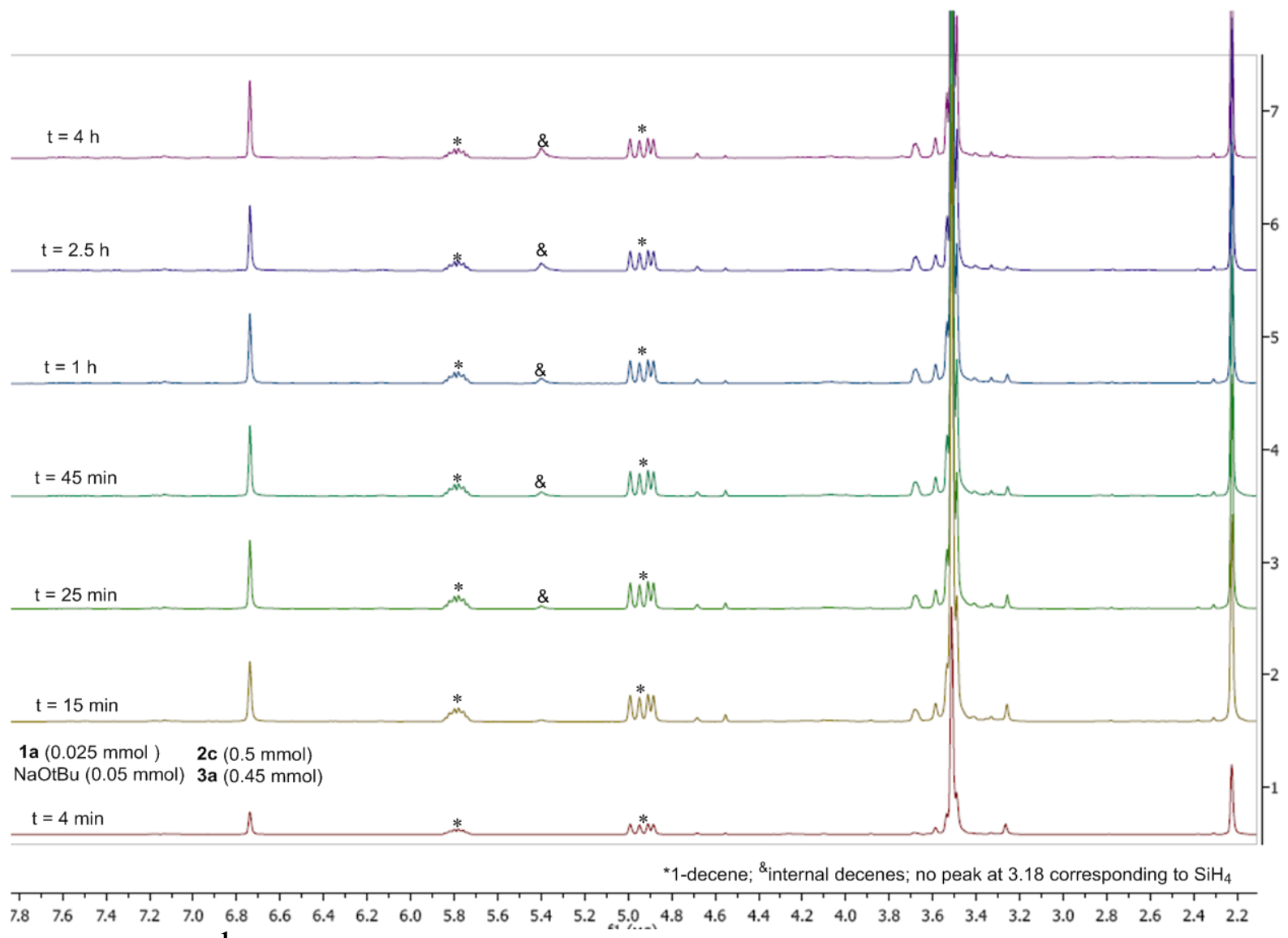

Fig. S5. Stack ${ }^{1}$ H NMR spectra of reaction 3a with $2 \mathrm{c}$ (THF-d8) 


\section{Monitoring of the reaction of $3 \mathrm{a}$ with $\mathbf{2 b}$}

In a nitrogen filled glovebox, an oven-dried vial was charged with 1-decene (3a) (84 mg, 0.6 mmol), $2 \mathbf{b}$ (100 mg, $0.75 \mathrm{mmol})$, mesitylene (10 mg, $0.083 \mathrm{mmol})$ and THF- $\mathrm{d}_{8}(0.6 \mathrm{~mL})$. The solution was placed in J. Young NMR tube and a solution of complex 1a (6 mg, $12 \mu \mathrm{mol})$ and $\mathrm{NaO}^{\mathrm{t}} \mathrm{Bu}(2.5 \mathrm{mg}, 26 \mu \mathrm{mol})$ in $0.4 \mathrm{~mL}$ of $\mathrm{THF}-\mathrm{d}_{8}$ was added. The tube was immediately closed and taken out. Outside the glovebox, the tube was shaken prior to introduction in to the NMR spectrometer. First measurement was made after 4 min from the moment when catalyst was added. (Fig. S6). No peak of $\mathrm{MeSiH}_{3}$ was observed in the course of reaction.

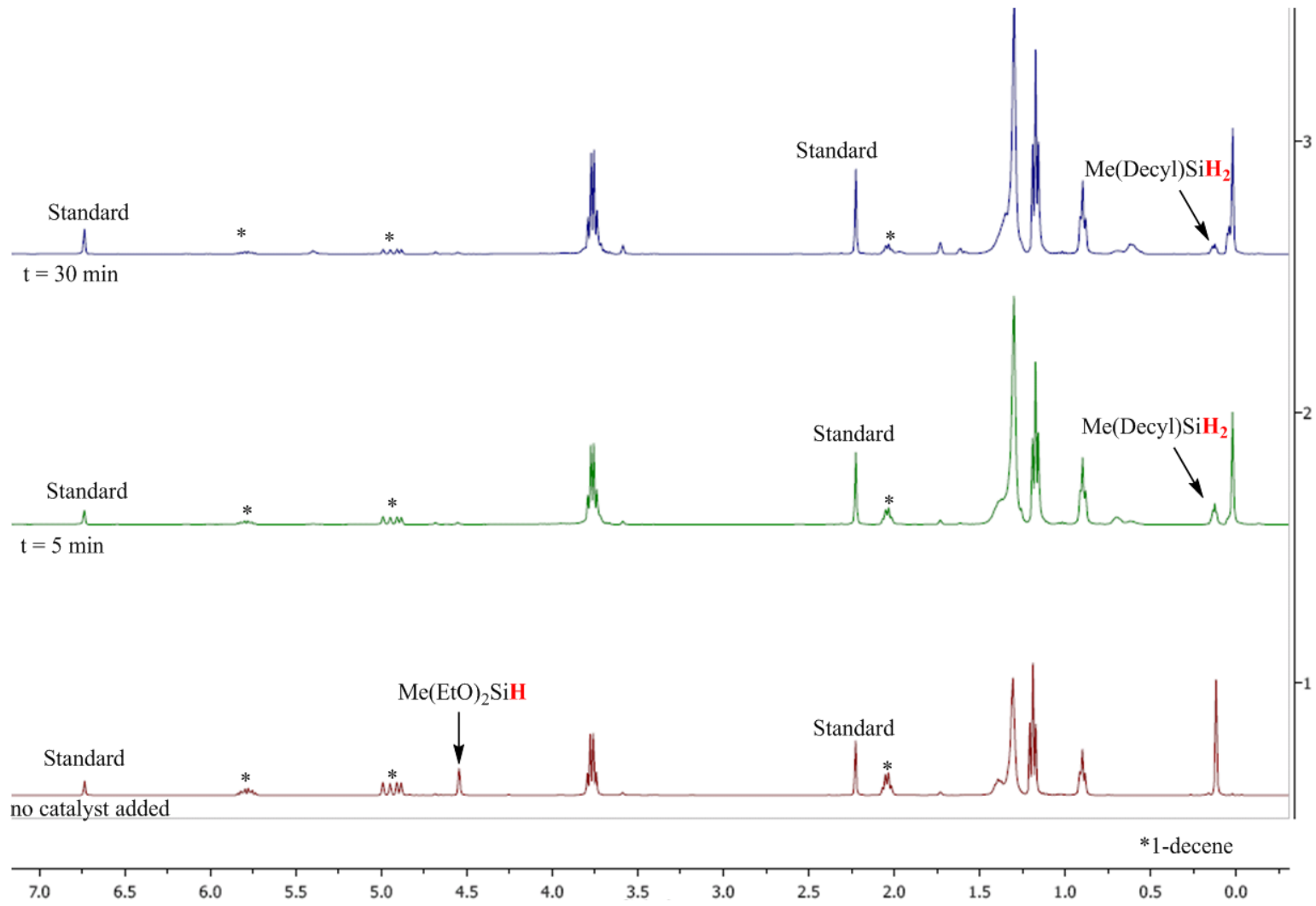

Fig. S6. Stack ${ }^{1}$ H NMR spectra of reaction 3a with 2 b (THF-d8) 
Stock solution of $\mathrm{NaO}^{t} \mathrm{Bu}$ was prepared from $12 \mathrm{mg}$ of $\mathrm{NaO}^{\mathrm{t}} \mathrm{Bu}$ and $10.0 \mathrm{~mL}$ of THF-d8.

In a nitrogen filled glovebox, an oven-dried vial was charged with $\mathbf{2 a}$ (23 $\mathrm{mg}, 0.25 \mathrm{mmol}$ ), mesitylene (9 mg, $0.075 \mathrm{mmol})$ and THF- $\mathrm{d}_{8}(0.5 \mathrm{~mL})$. The solution was placed in J. Young NMR tube and an aliquot of stock solution of $\mathrm{NaO}^{\mathrm{t}} \mathrm{Bu}(0.1 \mathrm{~mL}, 0.5 \%)$ in was added. The tube was closed and taken out. Outside the glovebox, the tube was shaken prior to introduction in to the NMR spectrometer. First measurement was made after 2 min from the moment when catalyst was added.

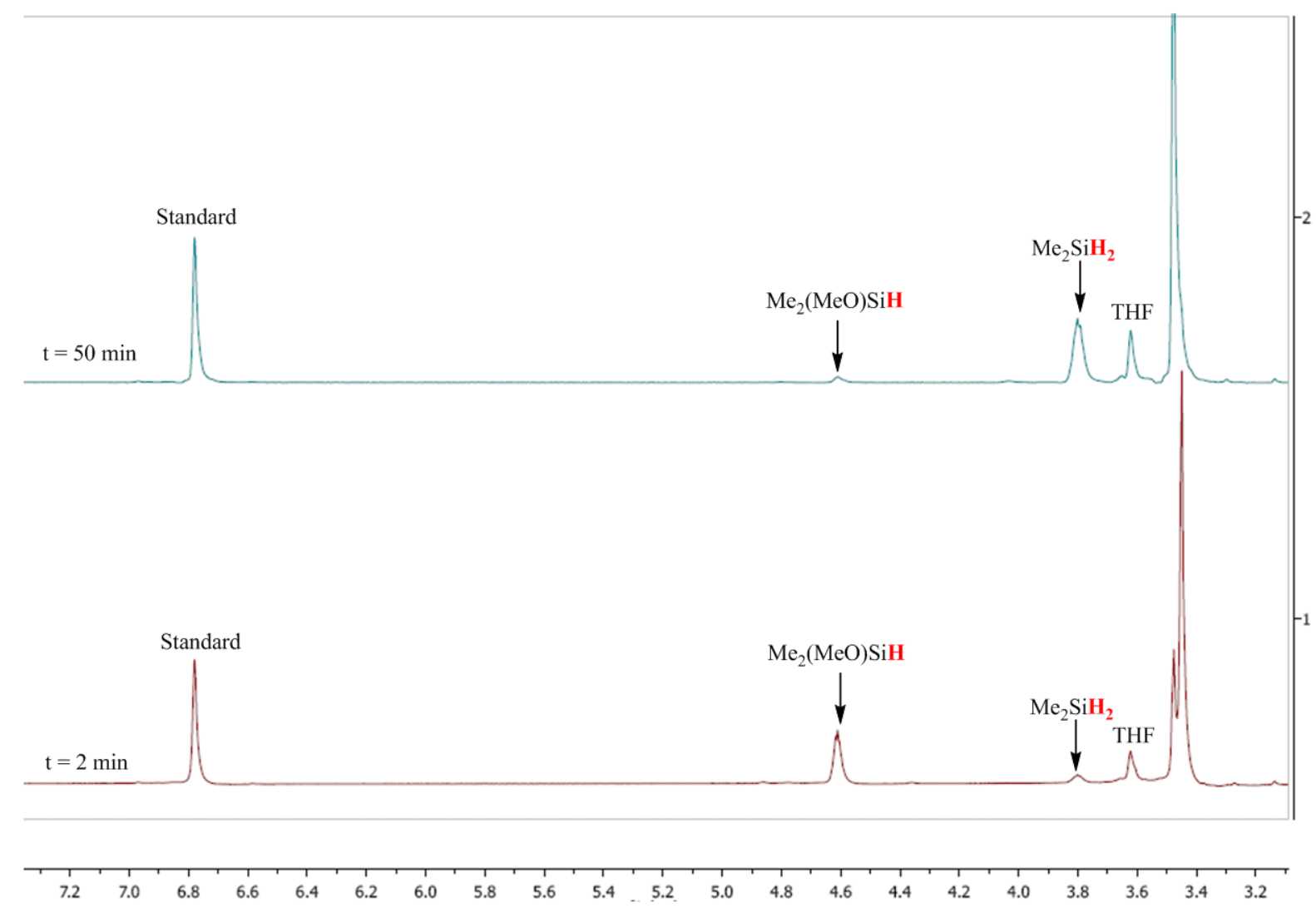

Fig. S7. Selected ${ }^{1} \mathrm{H}$ NMR spectra of the disproportionation of 2 a catalyzed by $0.5 \mathrm{~mol}$ $\%$ of $\mathrm{NaO}^{t} \mathrm{Bu}$. 


\section{Monitoring of the disproportionation of $2 \mathrm{~b}$}

In a nitrogen filled glovebox, an oven-dried vial was charged with $\mathbf{2 b}$ (34 $\mathrm{mg}, 0.25 \mathrm{mmol}$ ), mesitylene (9 mg, $0.075 \mathrm{mmol})$ and THF- $\mathrm{d}_{8}(0.5 \mathrm{~mL})$. The solution was placed in J. Young NMR tube and an aliquot of stock solution of $\mathrm{NaO}^{t} \mathrm{Bu}(0.1 \mathrm{~mL}, 0.5 \%)$ in was added. The tube was closed and taken out. Outside the glovebox, the tube was shaken prior to introduction in to the NMR spectrometer. First measurement was made after 2 min from the moment when catalyst was added.

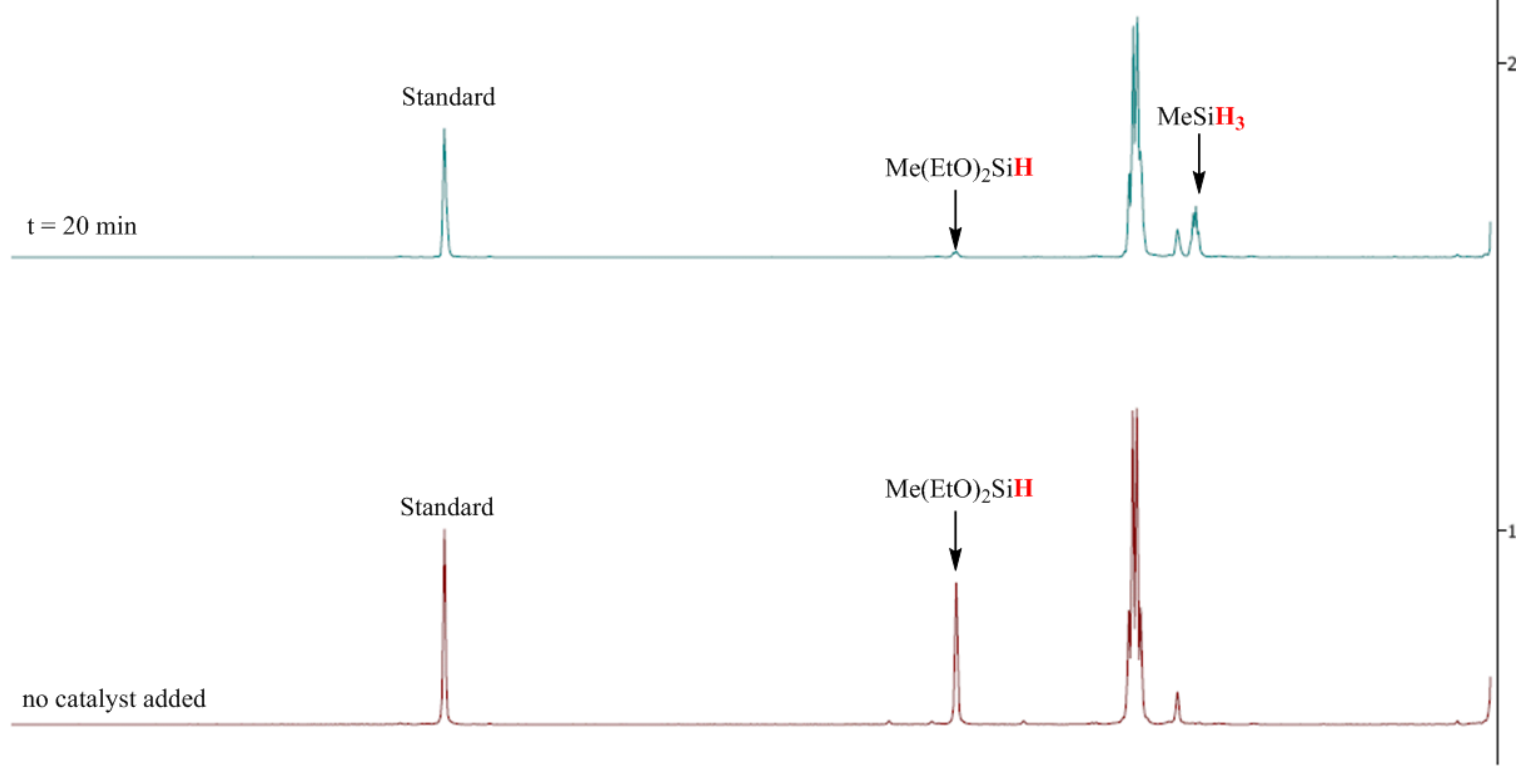

$\begin{array}{lllllllllllllllllllllllllllllllllllll}.6 & 8.4 & 8.2 & 8.0 & 7.8 & 7.6 & 7.4 & 7.2 & 7.0 & 6.8 & 6.6 & 6.4 & 6.2 & 6.0 & 5.8 & 5.6 & 5.4 & 5.2 & 5.0 & 4.8 & 4.6 & 4.4 & 4.2 & 4.0 & 3.8 & 3.6 & 3.4 & 3.2 & 3.0 & 2.8 & 2.6 & 2.4\end{array}$

Fig. S8. Selected ${ }^{1} \mathrm{H}$ NMR spectra of the disproportionation of $2 \mathrm{~b}$ catalyzed by $0.5 \mathrm{~mol}$ $\%$ of $\mathrm{NaO}^{t} \mathrm{Bu}$.

\section{Monitoring of the disproportionation of 2c}

In a nitrogen filled glovebox, an oven-dried vial was charged with $2 \mathbf{c}$ (31 $\mathrm{mg}, 0.25 \mathrm{mmol}$ ), mesitylene (9 mg, $0.075 \mathrm{mmol})$ and THF- $\mathrm{d}_{8}(0.6 \mathrm{~mL})$. The solution was placed in J. Young NMR tube and an aliquot of stock solution of $\mathrm{NaO}^{\mathrm{t}} \mathrm{Bu}(0.02 \mathrm{~mL}, 0.1 \mathrm{~mol} \%)$ in was added. The tube was closed and taken out. Outside the glovebox, the tube was shaken prior to introduction in to the NMR spectrometer. First measurement was made after 1 min from the moment when catalyst was added. 


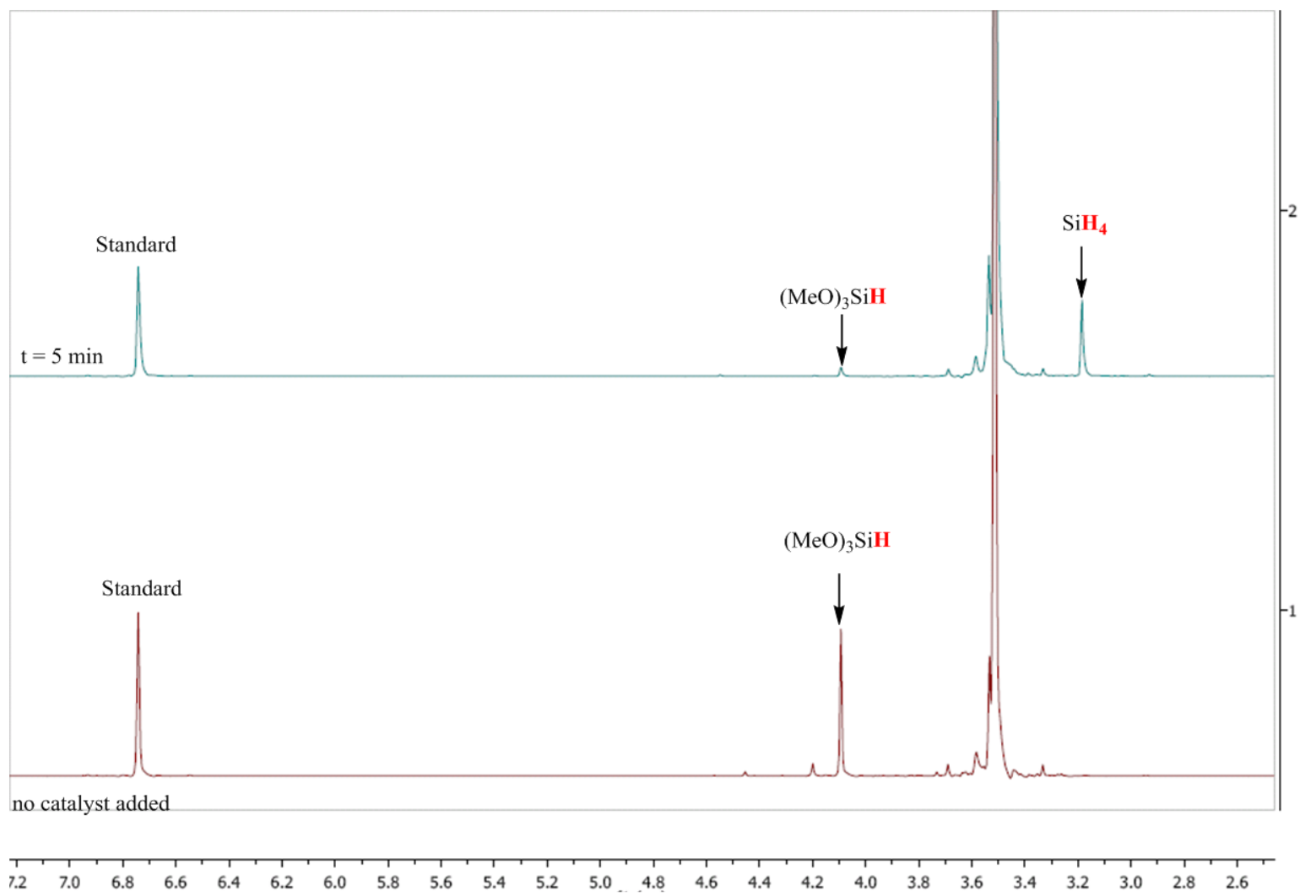

Fig. S9. Selected ${ }^{1} \mathrm{H}$ NMR spectra of the disproportionation of $2 \mathrm{c}$ catalyzed by $0.1 \mathrm{~mol}$ $\%$ of $\mathrm{NaO}^{t} \mathrm{Bu}$. 
Stock solution of $\mathbf{1 a}$ was prepared from $6 \mathrm{mg}$ of $\mathbf{1 a}$ and $1.0 \mathrm{~mL}$ of THF-d8

In a nitrogen filled glovebox, an oven-dried vial was charged with 2a (23 mg, $0.25 \mathrm{mmol}$ ), mesitylene (9 mg, $0.075 \mathrm{mmol})$ and THF- $\mathrm{d}_{8}(0.3 \mathrm{~mL})$. The solution was placed in J. Young NMR tube. Aliquots of the stock solutions of $\mathrm{NaO}^{t} \mathrm{Bu}(0.2 \mathrm{~mL}, 1.0 \mathrm{~mol} \%)$ and $\mathbf{1 a}(0.1 \mathrm{~mL}$, $0.5 \mathrm{~mol} \%$ ) were mixed in a separate vial, and after 10 minutes added to the NMR tube. The tube was closed and taken out. Outside the glovebox, the tube was shaken prior to introduction in to the NMR spectrometer. The rate of disproportionation was compared to that obtained in previous experiment where $0.5 \mathrm{~mol} \%$ of $\mathrm{NaO}^{\mathrm{t}} \mathrm{Bu}$ was the only catalyst.

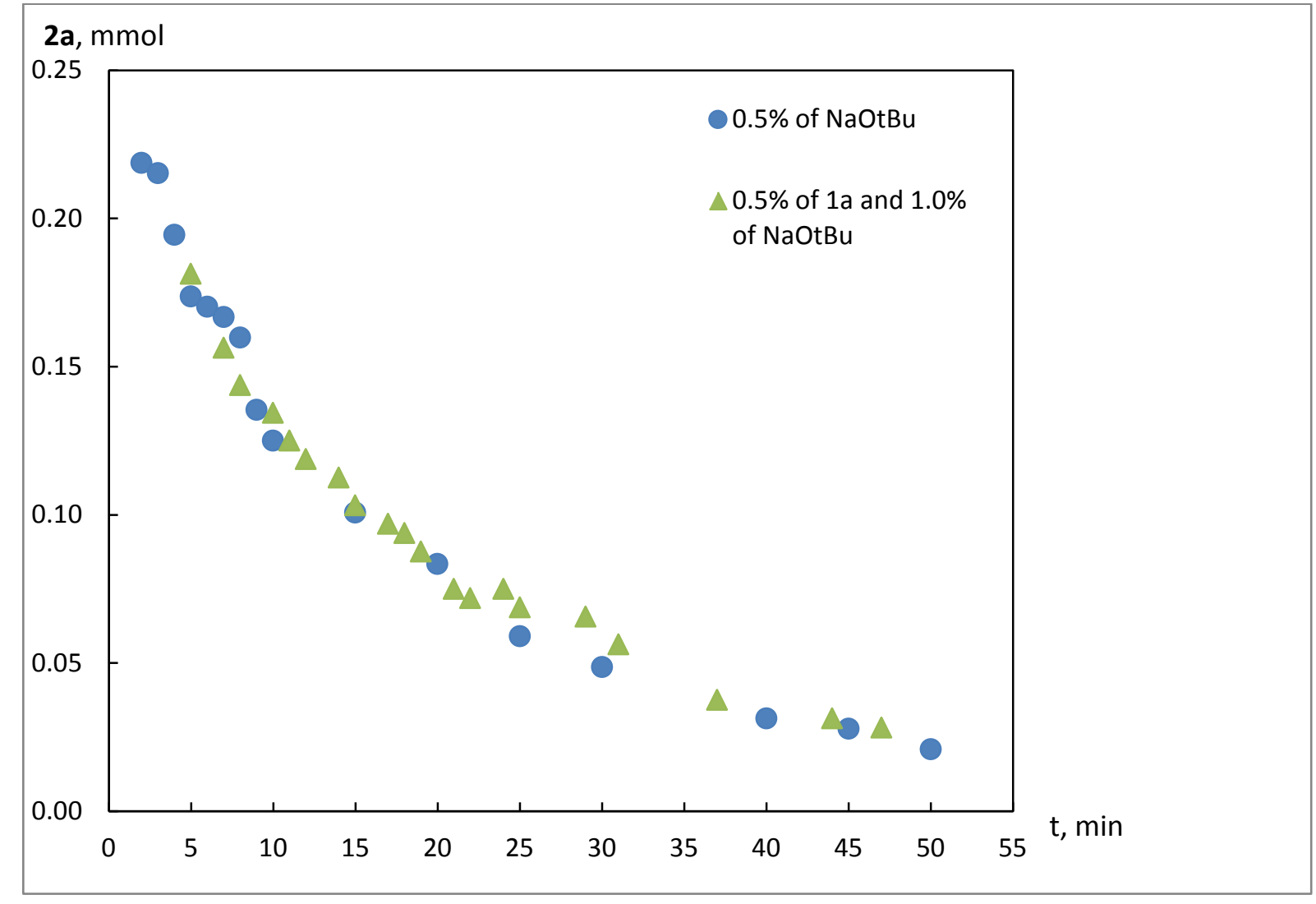

Fig. S10. Reaction profiles of disproportionation of 2a catalyzed by $0.5 \mathrm{~mol} \%$ of $\mathrm{NaO}^{t} \mathrm{Bu}$ and in the presence of $\mathrm{Ni}$ catalyst. 
In a nitrogen filled glovebox, an oven-dried vial was charged with 1-octadecene (3b) (37 mg, $0.15 \mathrm{mmol}$ ), dioctadecylsilane (6a) (67 mg, $0.125 \mathrm{mmol}$ ), mesitylene (10 $\mathrm{mg}, 0.083 \mathrm{mmol}$ ) and THF- $\mathrm{d}_{8}(0.6 \mathrm{~mL})$. The solution was placed in J. Young NMR tube and a solution of complex 1a (3 mg, $6 \mu \mathrm{mol})$ and $\mathrm{NaO}^{t} \mathrm{Bu}(1.5 \mathrm{mg}, 15 \mu \mathrm{mol})$ in $0.4 \mathrm{~mL}$ of THF-d 8 was added. The tube was closed and taken out. Outside the glovebox, the tube was shaken prior to introduction in to the NMR spectrometer. First measurement was made after 2 min from the moment when catalyst was added. (Fig. S11). Starting dioctadecylsilane was converted to trioctadecylsilane in 1 hour.
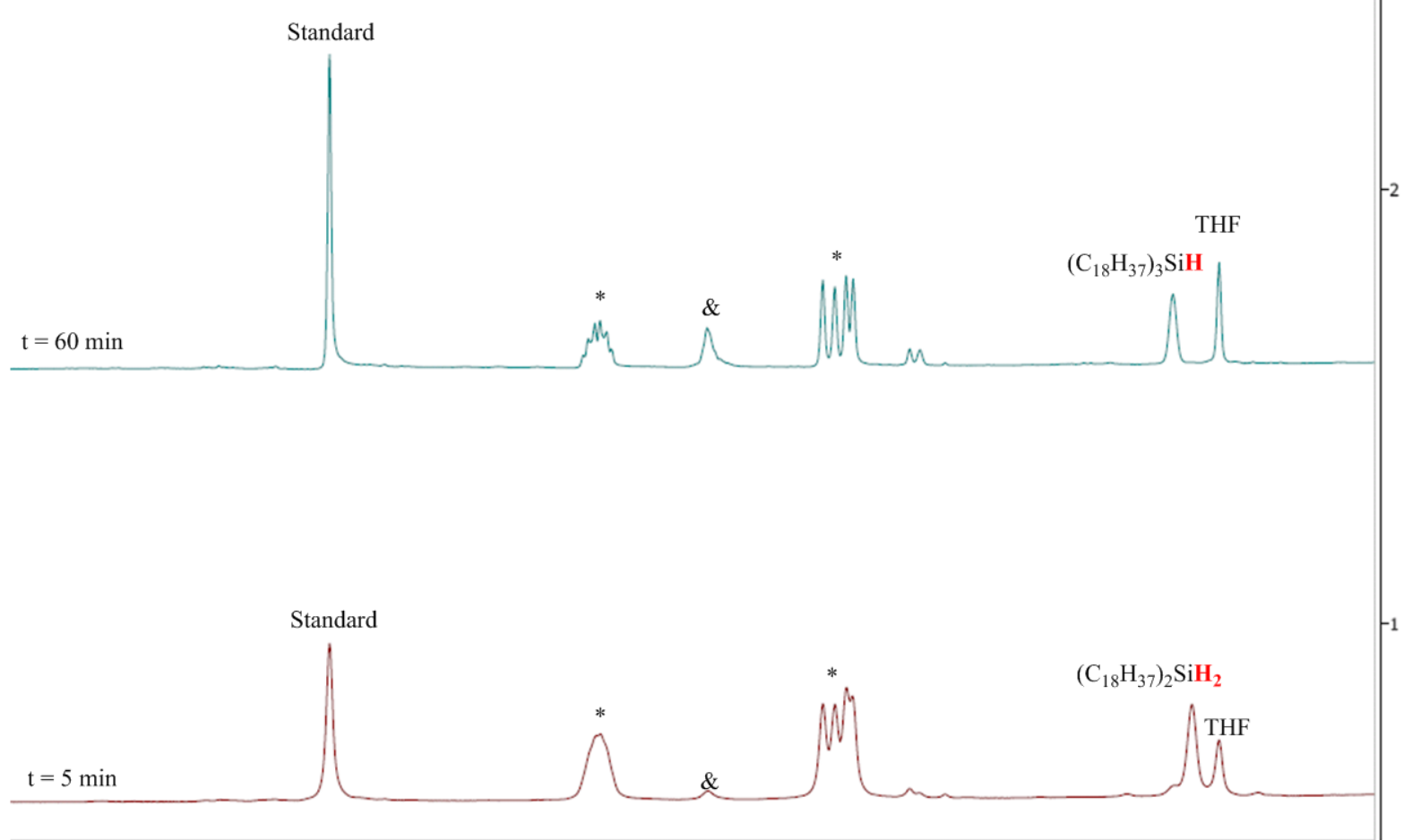

*1-octadecene; ${ }^{\&}$ internal octadecenes

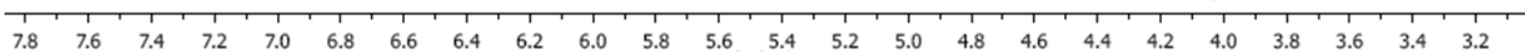

Fig. S11. Selected ${ }^{1}$ H NMR spectra of reaction 6 a with 1-octadecene (THF-d8) 
In a nitrogen filled glovebox, an oven-dried vial was charged with 1-octadecene (3b) (37 mg, $0.15 \mathrm{mmol}$ ), dioctadecylsilane (6a) (67 mg, $0.125 \mathrm{mmol}$ ), mesitylene (10 mg, $0.083 \mathrm{mmol}$ ), $(\mathrm{MeO})_{4} \mathrm{Si}(57 \mathrm{mg}, 0.375 \mathrm{mmol})$ and THF-d 8 (0.6 mL). The solution was placed in J. Young NMR tube and a solution of complex 1a (3 mg, $6 \mu \mathrm{mol})$ and $\mathrm{NaOtBu}(1.5 \mathrm{mg}, 15 \mu \mathrm{mol})$ in $0.4 \mathrm{~mL}$ of THF- $\mathrm{d}_{8}$ was added. The tube was closed and taken out. Outside the glovebox, the tube was shaken prior to introduction in to the NMR spectrometer. First measurement was made after 5 min from the moment when catalyst was added. Starting dioctadecylsilane did not disappear after 10 hours. The spectrum recordered after 6 hours shows $<40 \%$ conversion (Fig. S12).

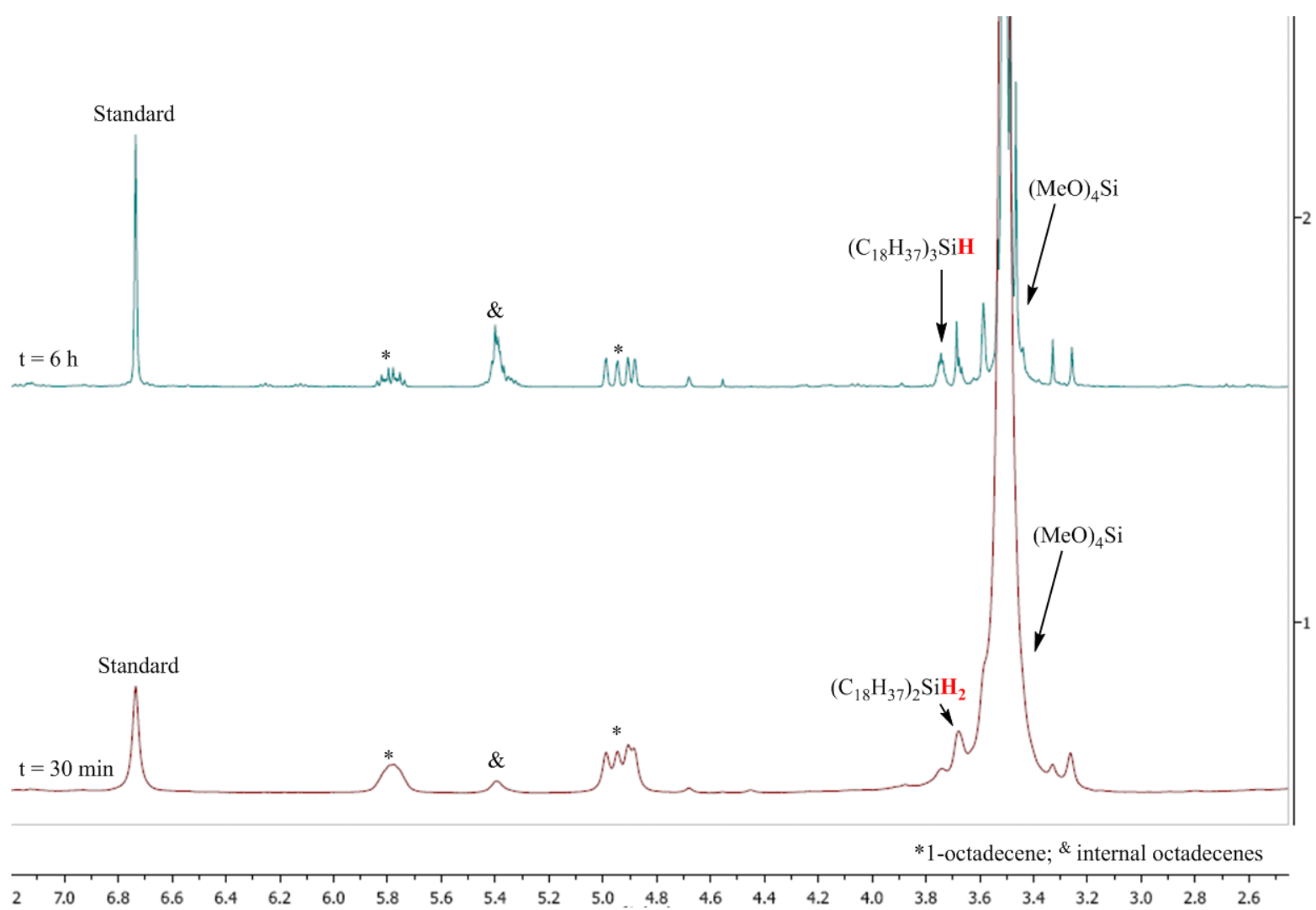

Fig. S12. Selected ${ }^{1} \mathrm{H}$ NMR spectra of reaction 6 a with 1-octadecene in the presence of 3 equiv. of (MeO) $)_{4} \mathrm{Si}$ (THF-d8) 


\section{Detailed descriptions of the products}

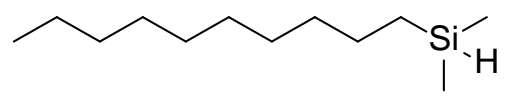

\section{Dimethyl(decyl)silane (4a)}

Following the general procedure I, the title compound was prepared using 1-decene (70 mg) and dimethylmethoxysilane (108 mg). The crude product was purified by flash chromatography using hexane as an eluent to afford the title compound (4a) as colorless oil (90 mg, 90\%).

${ }^{1}$ H NMR (400 MHz, $\mathrm{CDCl}_{3}$ ) 3.86-3.81 (m, 1H), 1.36-1.26 (m, 16H), 0.88 (t, $\left.J=6.3 \mathrm{~Hz}, 3 \mathrm{H}\right)$, 0.60-0.55 (m, 2H), 0.06 (d, $J=3.6 \mathrm{~Hz}, 6 \mathrm{H})$.

${ }^{13}$ C NMR (101 MHz, $\left.\mathrm{CDCl}_{3}\right) \delta 33.4,32.1,29.9,29.8,29.6,29.5,24.5,22.9,14.34,14.28$, 4.3.

Elemental analysis: Anal. Calcd for $\mathrm{C}_{12} \mathrm{H}_{28} \mathrm{Si}$ : C, 71.91; H, 14.08. Found: C, 71.52 ; H, 14.28 .<smiles>C[SiH](C)[15NH2]</smiles>

\section{Dimethyl(octadecyl)silane (4b)}

Following the general procedure I, the title compound was prepared using 1-octadecene (126 $\mathrm{mg}$ ) and dimethylmethoxysilane (108 mg). The crude product was purified by flash chromatography using hexane as an eluent to afford the title compound (4b) as colorless oil (145 mg, 93\%).

${ }^{1}$ H NMR (400 MHz, $\mathrm{CDCl}_{3}$ ) 3.86-3.81 (m, 1H), 1.35-1.25 (m, 32H), 0.88 (t, $\left.J=6.2 \mathrm{~Hz}, 3 \mathrm{H}\right)$, 0.60-0.55 (m, 2H), 0.06 (d, $J=3.6 \mathrm{~Hz}, 6 \mathrm{H})$.

${ }^{13}$ C NMR (101 MHz, CDCl3) $\delta$ 33.4, 32.2, 29.93, 29.89, 29.82, 29.61, 29.59, 24.58, 22.9, $14.4,14.3,-4.3$.

The spectroscopic data corresponds to that available on Sigma-Aldrich database (product 276138)

Elemental analysis: Anal. Calcd for $\mathrm{C}_{20} \mathrm{H}_{44} \mathrm{Si}$ : C, 76.83; H, 14.19. Found : C, 76.46 ; H, 14.21.

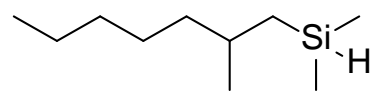

\section{Dimethyl(2-methylheptyl)silane (4c)}


Following the general procedure I, the title compound was prepared using 2-methyl-2heptene (56 mg) and dimethylmethoxysilane (108 mg). The crude product was purified by flash chromatography using hexane as an eluent to afford the title compound (4c) as colorless oil (25 mg, 29\%).

${ }^{1}$ H NMR (400 MHz, $\left.\mathrm{CDCl}_{3}\right) \delta$ 3.92-3.87 (m, 1H), 1.62-1.56 (m, 1H), 1.32-1.16 (m, 8H), 0.92-0.87 (m, 6H), 0.71-0.66 (m, 1H), 0.51-0.44 (m, 1H), 0.07 (d, $J=3.6 \mathrm{~Hz}, 6 \mathrm{H})$.

${ }^{13}$ C NMR (101 MHz, $\left.\mathrm{CDCl}_{3}\right) \delta 40.3,32.3,30.0,27.0,23.0,22.9,22.7,14.3,-3.6$.

Elemental analysis: Anal. Calcd for $\mathrm{C}_{10} \mathrm{H}_{24} \mathrm{Si}$ : C, 69.67; H, 14.03. Found : C, 69.49 ; H, 14.14.<smiles>C[Si](C)CCCc1ccccc1</smiles>

\section{Dimethyl(3-phenylpropyl)silane (4d)}

Following the general procedure I, the title compound was prepared using allylbenzene (59 mg) and dimethylmethoxysilane (108 mg). The crude product was purified by flash chromatography using hexane as an eluent to afford the title compound (4d) as colorless oil (72 mg, 81\%).

${ }^{1}$ H NMR (400 MHz, $\left.\mathrm{CDCl}_{3}\right) \delta$ 7.34-7.30 (m, 2H), 7.22-7.20 (m, 3H), 3.94-3.90 (m, 1H), 2.68 (t, $J=7.8 \mathrm{~Hz}, 2 \mathrm{H}), 1.76-1.68$ (m, 2H), 0.70-0.65 (m, 2H), 0.11 (d, $J=3.6 \mathrm{~Hz}, 6 \mathrm{H})$.

${ }^{13}$ C NMR (101 MHz, $\left.\mathrm{CDCl}_{3}\right) \delta$ 142.7, 128.6, 128.4, 125.8, 39.6, 26.7, 14.1, -4.3.

HRMS (APPI): calculated for $\left(\mathrm{C}_{11} \mathrm{H}_{17} \mathrm{Si},[\mathrm{M}-\mathrm{H}]^{+}\right), 177.1100$ found 177.1107 .<smiles>C[Si](C)(C)CCC1CC=CCC1</smiles>

\section{(2-(Cyclohex-3-en-1-yl)ethyl)dimethylsilane (4e)}

Following the general procedure I, the title compound was prepared using 4-vinylhexene (54 mg) and dimethylmethoxysilane (108 mg). The crude product was purified by flash chromatography using hexane as an eluent to afford the title compound (4e) as colorless oil (71 mg, 85\%).

${ }^{1}$ H NMR (400 MHz, $\left.\mathrm{CDCl}_{3}\right) \delta$ 5.69-5.63 (m, 2H), 3.87-3.83 (m, 1H), 2.15-2.03 (m, 3H), 1.78-1.75 (m, 1H), 1.65-1.59 (m, 1H), 1.50-1.42 (m, 1H), 1.33-1.26 (m, 2H), 1.24-1.16 (m, $1 \mathrm{H}), 0.63-0.58$ (m, 2H), 0.07 (d, $J=3.6 \mathrm{~Hz}, 6 \mathrm{H})$.

${ }^{13}$ C NMR (101 MHz, $\left.\mathrm{CDCl}_{3}\right) \delta 127.2,126.8,36.5,31.8,31.3,28.7,25.5,11.3,-4.3$.

HRMS (APPI): calculated for $\left(\mathrm{C}_{10} \mathrm{H}_{19} \mathrm{Si},[\mathrm{M}-\mathrm{H}]^{+}\right), 167.1251$ found 167.1252 . 
<smiles>C[Si](C)(C)CCCCCCOCc1ccccc1</smiles>

\section{(6-(Benzyloxy)hexyl)dimethylsilane (4f)}

Following the general procedure I, the title compound was prepared using 6-(benzyloxy)hex1-ene (3f) (95 mg) and dimethylmethoxysilane (108 mg). The crude product was purified by flash chromatography using hexane as an eluent to afford the title compound (4f) as colorless oil (115 mg, 92\%).

${ }^{1}$ H NMR (400 MHz, $\left.\mathrm{CDCl}_{3}\right) \delta$ 7.33-7.24 (m, 5H), 4.49 (s, 2H), 3.86-3.82 (m, 1H), 3.45 (t, J $=6.6 \mathrm{~Hz}, 2 \mathrm{H}), 1.65-1.57(\mathrm{~m}, 2 \mathrm{H}), 1.38-1.30(\mathrm{~m}, 6 \mathrm{H}), 0.60-0.54(\mathrm{~m}, 2 \mathrm{H}), 0.05$ (d, $J=3.6 \mathrm{~Hz}$, $6 \mathrm{H})$.

${ }^{13}$ C NMR (101 MHz, $\left.\mathrm{CDCl}_{3}\right) \delta 138.8,128.4,127.7,127.6,73.0,70.6,33.1,29.8,26.0,24.4$, 14.2, -4.3 .

HRMS (ESI): calculated for $\left(\mathrm{C}_{15} \mathrm{H}_{27} \mathrm{OSi},[\mathrm{M}+\mathrm{H}]^{+}\right), 251.1831$ found 251.1823 .

\section{$115 \mathrm{mg}, 92 \%$}

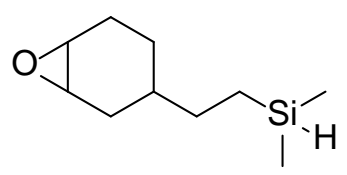

\section{(2-(7-Oxabicyclo[4.1.0]heptan-3-yl)ethyl)dimethylsilane ( mixture of isomers) (4g)}

Following the general procedure I, the title compound was prepared using 4-vinyl-1cyclohexene 1,2-epoxide, (mixture of isomers) $\mathbf{( 3 g}) \quad(62 \mathrm{mg}, 0.5 \mathrm{mmol}$ ) and dimethylmethoxysilane $(250 \mathrm{mg}, 2.78 \mathrm{mmol}$ ). The crude product was purified by flash chromatography using hexane as an eluent to afford the title compound (4g) as colorless oil (86 mg, 93\%).

${ }^{1}$ H NMR (400 MHz, $\left.\mathrm{CDCl}_{3}\right) \delta$ 3.83-3.75 (m, 1H), 3.14-3.06 (m, 2H), 2.17-1.93 (m, 2H), 1.82-1.62 (m, 1H), 1.50-1.01 (m, 6H), 0.52-0.42 (m, 2H), 0.10-0.01 (m, 6H).

${ }^{13}$ C NMR (101 MHz, $\left.\mathrm{CDCl}_{3}\right) \delta$ 53.3, 52.8, 52.0, 51.9, 35.4, 32.3, 31.6, 31.4, 30.9, 30.5, 26.8, 25.4, 24.1, 23.7, 11.2, 11.0, -4.47.

HRMS (ESI): calculated for $\left(\mathrm{C}_{10} \mathrm{H}_{21} \mathrm{OSi},[\mathrm{M}+\mathrm{H}]^{+}\right), 185.1356$ found 185.1358.<smiles>C[SiH](C)CCCCCCO[Si](C)(C)C(C)(C)C</smiles>

Tert-butyl((6-(dimethylsilyl)hexyl)oxy)dimethylsilane (4h) 
Following the general procedure I, the title compound was prepared using tert-butyl(hex-5en-1-yloxy)dimethylsilane (3h) (107 mg) and dimethylmethoxysilane (108 mg). The crude product was purified by flash chromatography using hexane as an eluent to afford the title compound (4h) as colorless oil (114 mg, 83\%).

${ }^{1}$ H NMR (400 MHz, $\left.\mathrm{CDCl}_{3}\right) \delta$ 3.86-3.81 (m, 1H), $3.60(\mathrm{t}, J=6.6 \mathrm{~Hz}, 2 \mathrm{H}), 1.54-1.47$ (m, 2H), 1.37-1.28 (m, 6H), 0.89 (s, 9H), 0.60-0.55 (m, 2H), 0.10 (m, 12H).

${ }^{13}$ C NMR (101 MHz, $\left.\mathrm{CDCl}_{3}\right) \delta$ 63.5, 33.1, 33.0, 26.2, 25.7, 24.5, 18.6, 14.3, -4.3, -5.1.

HRMS (APCI): calculated for $\left(\mathrm{C}_{14} \mathrm{H}_{34} \mathrm{OSi}_{2},[\mathrm{M}+\mathrm{H}]^{+}\right), 275.2221$ found 275.2212 .<smiles>C[SiH](C)CCCCCCOC1CCCCO1</smiles>

\section{Dimethyl(6-((tetrahydro-2H-pyran-2-yl)oxy)hexyl)silane (4i)}

Following the general procedure I, the title compound was prepared using 6-(2tetrahydropyranyl)oxy-l-hexene (3i) (92 mg) and dimethylmethoxysilane (108 mg). The crude product was purified by flash chromatography using hexane/EtOAc (20:1) as an eluent to afford the title compound (4i) as colorless oil (108 $\mathrm{mg}, 89 \%)$.

${ }^{1}$ H NMR (400 MHz, $\left.\mathrm{CDCl}_{3}\right) \delta$ 4.58-4.56 (m, 1H), 3.89-3.82 (m, 2H), 3.76-3.70 (m, 1H), 3.52-3.46 (m, 1H), 3.41-3.35 (m, 1H), 1.86-1.81 (m, 1H), 1.75-1.69 (m, 1H), 1.64-1.50 (m, $6 \mathrm{H}), 1.39-1.35$ (m, 6H), 0.60-0.54 (m, 2H), 0.02 (d, $J=3.6 \mathrm{~Hz}, 6 \mathrm{H})$.

${ }^{13}$ C NMR (101 MHz, $\left.\mathrm{CDCl}_{3}\right) \delta$ 98.9, 67.7, 62.3, 33.1, 30.9, 29.7, 26.0, 25.6, 24.4, 19.8, 14.2, -4.4 .

HRMS (ESI): calculated for $\left(\mathrm{C}_{13} \mathrm{H}_{29} \mathrm{O}_{2} \mathrm{Si},[\mathrm{M}+\mathrm{H}]^{+}\right), 245.1937$ found 245.1940 .

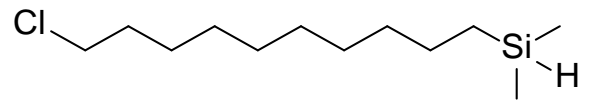

\section{(10-chlorodecyl)dimethylsilane $(4 \mathrm{j})$}

Following the general procedure I, the title compound was prepared using 10-chlorohex-1ene (87 mg) and dimethylmethoxysilane (180 mg). The crude product was purified by flash chromatography using hexane as an eluent to afford the title compound (4j) as yellowish oil (85mg, 72\%).

${ }^{1} \mathbf{H}$ NMR (400 MHz, $\left.\mathrm{CDCl}_{3}\right) \delta$ 3.88-3.81 (m, 1H), $3.53(\mathrm{t}, \mathrm{J}=6.6 \mathrm{~Hz}, 2 \mathrm{H}), 1.80-1.73(\mathrm{~m}$, 2H), 1.45-1.38 (m, 2H), 1.31-1.23 (m, 12H), 0.60-0.54 (m, 2H), 0.05 (d, $J=2.7 \mathrm{~Hz}, 6 \mathrm{H})$.

${ }^{13}$ C NMR (101 MHz, $\left.\mathrm{CDCl}_{3}\right) \delta 45.3,33.3,32.8,29.6,29.6,29.5,29.0,27.1,24.5,14.3,-4.3$.

Elemental analysis: Anal. Calcd for $\mathrm{C}_{12} \mathrm{H}_{27} \mathrm{ClSi}$ : C, 61.36; H, 11.59. Found: $\mathrm{C}, 61.53$; $\mathrm{H}$, 11.48 . 


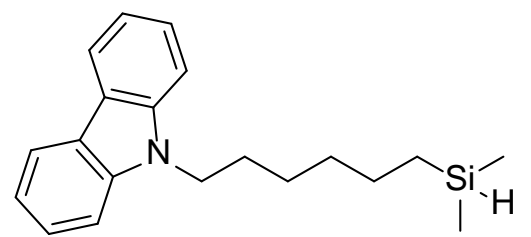

\section{9-(6-(Dimethylsilyl)hexyl)-9H-carbazole (4k)}

Following the general procedure I, the title compound was prepared using 9-(hex-5-en-1-yl)9H-carbazole (3k) (125 mg) and dimethylmethoxysilane (108 mg). The crude product was purified by flash chromatography using hexane/EtOAc (20:1) as an eluent to afford the title compound (4k) as colorless oil (140 mg, 91\%).

${ }^{1}$ H NMR (400 MHz, $\mathrm{CDCl}_{3}$ ) $\delta 8.14$ (d, J = 7.8 Hz, 2H), 7.50 (m, 2H), 7.44 (d, J = 8.1 Hz, 2H), 7.27 (m, 2H), 4.33 (t, J = 7.2 Hz, 2H), 3.87-3.85 (m, 1H), 1.93-1.89 (m, 2H), 1.42-1.33 (m, 6H), 0.60-0.58 (m, 2H), 0.08 (d, $J=3.6 \mathrm{~Hz}, 6 \mathrm{H})$.

${ }^{13}$ C NMR (101 MHz, $\left.\mathrm{CDCl}_{3}\right) \delta 140.6,125.7,123.0,120.5,118.8,108.8,43.2,33.1,29.0$, 27.2, 24.4, 14.3, -4.3 .

HRMS (ESI): calculated for $\left(\mathrm{C}_{20} \mathrm{H}_{28} \mathrm{NSi},[\mathrm{M}+\mathrm{H}]^{+}\right)$, 310.1991 found 310.1996 .<smiles>C[SiH](C)CCCC(C)(C)C1OCCO1</smiles>

\section{(4-(1,3-Dioxolan-2-yl)-4-methylpentyl)dimethylsilane (4l)}

Following the general procedure I, the title compound was prepared using 2,2-dimethyl-4pentenal ethylene acetal (3l) (78 mg) and dimethylmethoxysilane (108 mg). The crude product was purified by flash chromatography using hexane/EtOAc (20:1) as an eluent to afford the title compound (4I) as colorless oil (94 mg, 87\%).

${ }^{1}$ H NMR (400 MHz, $\mathrm{CDCl}_{3}$ ) $\delta 4.51$ (s, 1H), 3.92-3.81 (m, 5H), 1.36-1.30 (m, 4H), 0.86 (s, $6 \mathrm{H}), 0.58-0.50$ (m, 2H), 0.04 (d, $J=3.6 \mathrm{~Hz}, 6 \mathrm{H})$

${ }^{13}$ C NMR (101 MHz, $\left.\mathrm{CDCl}_{3}\right) \delta 110.1,65.3,41.7,37.4,21.5,18.5,15.3,-4.2$.

Elemental analysis: Anal. Calcd for $\mathrm{C}_{11} \mathrm{H}_{24} \mathrm{O}_{2} \mathrm{Si}$ : C, 61.05; H, 11.18. Found: C, 61.36 ; H, 11.47.

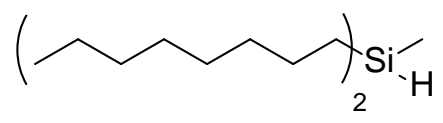

Methyldioctylsilane (5a) 
Following the general procedure II, the title compound was prepared using 1-octene (134 mg, $1.2 \mathrm{mmol}$ ) and methyldiethoxysilane (201 mg, $1.5 \mathrm{mmol}$ ). The crude product was purified by flash chromatography using hexane as an eluent to afford the title compound (5a) as colorless oil (101 mg, 75\%).

${ }^{1}$ H NMR (400 MHz, $\left.\mathrm{CDCl}_{3}\right) \delta$ 3.78-3.71 (m, 1H), 1.39-1.21 (m, 24H), 0.88 (t, J = 5.8 Hz, 6H), 0.63-0.49 (m, 4H), 0.03 (d, J = 3.0 Hz, 3H).

${ }^{13}$ C NMR $\left(101 \mathrm{MHz}, \mathrm{CDCl}_{3}\right) \delta 33.5,32.1,29.5,29.4,24.7,22.9,14.3,12.9,-6.1$.

HRMS (APPI): calculated for $\left(\mathrm{C}_{17} \mathrm{H}_{37} \mathrm{Si},[\mathrm{M}-\mathrm{H}]^{+}\right)$, 269.2664 found 269.2679.<smiles>C[AsH2][Si](C)([14CH3])[13CH2][13CH3]</smiles>

\section{Methyldioctadecylsilane (5b)}

Following the general procedure II, the title compound was prepared using 1-octadecene (302 mg, $1.2 \mathrm{mmol}$ ) and methyldiethoxysilane (201 $\mathrm{mg}, 1.5 \mathrm{mmol})$. The crude product was purified by flash chromatography using hexane as an eluent to afford the title compound (5b) as white solid (210 $\mathrm{mg}, 76 \%$ ).

${ }^{1}$ H NMR (400 MHz, $\left.\mathrm{CDCl}_{3}\right) \delta$ 3.79-3.73 (m, 1H), 1.42-1.15 (m, 64H), $0.88(\mathrm{t}, \mathrm{J}=6.5 \mathrm{~Hz}$, $6 \mathrm{H}), 0.64-0.52(\mathrm{~m}, 4 \mathrm{H}), 0.04(\mathrm{~d}, \mathrm{~J}=3.0 \mathrm{~Hz}, 3 \mathrm{H})$.

${ }^{13}$ C NMR (101 MHz, $\left.\mathrm{CDCl}_{3}\right) \delta$ 33.5, 32.1, 29.9, 29.8, 29.6, 24.7, 22.9, 14.3, 13.0, -6.0.

Elemental analysis: Anal. Calcd for $\mathrm{C}_{37} \mathrm{H}_{78} \mathrm{Si}$ : C, 80.64; H, 14.27. Found: $\mathrm{C}, 80.71$; H, 14.18.

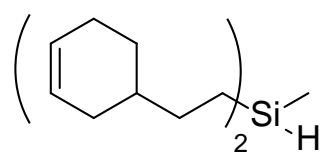

\section{Bis(2-(cyclohex-3-en-1-yl)ethyl)(methyl)silane (5c)}

Following the general procedure II, the title compound was prepared using 4-vinylhexene (130 mg, $1.2 \mathrm{mmol}$ ) and methyldiethoxysilane (201 mg, $1.5 \mathrm{mmol})$. The crude product was purified by flash chromatography using hexane as an eluent to afford the title compound (5c) as colorless oil (96 mg, 73\%).

${ }^{1}$ H NMR (400 MHz, $\left.\mathrm{CDCl}_{3}\right) \delta$ 5.68-5.63 (m, 4H), 3.79-3.75 (m, 1H), 2.14-2.02 (m, 6H), 1.78-1.74 (m, 2H), 1.66-1.57 (m, 2H), 1.52-1.43 (m, 2H), 1.33-1.27 (m, 4H), 1.23-1.13 (m, 2H), 0.65-0.54 (m, 4H), 0.05 (d, $J=3.6 \mathrm{~Hz}, 3 \mathrm{H})$.

${ }^{13}$ C NMR (101 MHz, $\left.\mathrm{CDCl}_{3}\right) \delta$ 127.2, 126.8, 36.5, 31.8, 31.4, 28.7, 25.5, 9.8, -6.2.

HRMS (ESI): calculated for $\left(\mathrm{C}_{17} \mathrm{H}_{30} \mathrm{Si},\left[\mathrm{M}^{+\bullet}\right]\right), 262.2111$ found 262.2112 
<smiles>CC(C)(C)[Si](C)(C)CCCCO[Si](C)(C)C</smiles>

\section{Bis(tert-butyl((6-(dimethylsilyl)hexyl)oxy)(methyl)silane (5d)}

Following the general procedure II, the title compound was prepared using tert-butyl(hex-5en-1-yloxy)dimethylsilane (3h) (256 mg, $1.2 \mathrm{mmol}$ ) and methyldiethoxysilane (201 mg, 1.5 mmol). The crude product was purified by flash chromatography using hexane/EtOAc (20:1) as an eluent to afford the title compound (5d) as yellowish oil (174 mg, 73\%).

${ }^{1}$ H NMR (400 MHz, $\left.\mathrm{CDCl}_{3}\right) \delta$ 3.76-3.74 (m, 1H), $3.60(\mathrm{t}, J=6.5 \mathrm{~Hz}, 4 \mathrm{H}), 1.52-1.49$ (m, 4H), 1.37-1.29 (m, 12H), 0.89 (s, 18H), 0.62-0.53 (m, 4H), 0.05-0.03 (m, 15H).

${ }^{13}$ C NMR (101 MHz, $\left.\mathrm{CDCl}_{3}\right) \delta$ 63.5, 33.2, 33.0, 26.2, 25.7, 24.6, 18.5, 12.9, -5.1, -6.1.

Elemental analysis: Anal. Calcd for $\mathrm{C}_{25} \mathrm{H}_{58} \mathrm{O}_{2} \mathrm{Si}_{3}$ : C, 63.22; $\mathrm{H}, 12.31$. Found: $\mathrm{C}, 63.21$; $\mathrm{H}$, 12.42 .

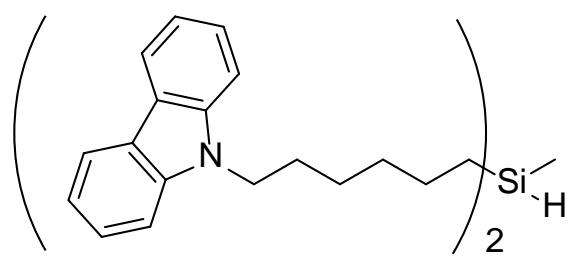

\section{9,9'-((Methylsilanediyl)bis(hexane-6,1-diyl))bis(9H-carbazole) (5e)}

Following the general procedure II, the title compound was prepared using 9-(hex-5-en-1-yl)9H-carbazole (3k) (300 mg, $1.2 \mathrm{mmol}$ ) and methyldiethoxysilane (201 mg, $1.5 \mathrm{mmol}$ ). The crude product was purified by flash chromatography using hexane/EtOAc (10:1) as an eluent to afford the title compound (5e) as colorless oil (214 mg, 79\%).

${ }^{1}$ H NMR (400 MHz, $\left.\mathrm{CDCl}_{3}\right) \delta 8.18(\mathrm{~d}, \mathrm{~J}=7.7 \mathrm{~Hz}, 4 \mathrm{H}), 7.53(\mathrm{~m}, 4 \mathrm{H}), 7.46$ (d, J = 8.2 Hz, 4H), 7.31 (m, 4H), 4.33 (t, J = 7.1 Hz, 4H), 3.84-3.78 (m, 1H), 1.94-1.90 (m, 4H), 1.43-1.33 (m, 12H), 0.62-0.58 (m, 4H), 0.08 (d, $J=3.2 \mathrm{~Hz}, 3 \mathrm{H})$.

${ }^{13}$ C NMR (101 MHz, $\left.\mathrm{CDCl}_{3}\right) \delta 140.5,125.7,122.9,120.5,118.8,108.8,43.1,33.1,29.8$, $27.1,24.5,12.8,-6.1$.

HRMS (ESI): calculated for $\left(\mathrm{C}_{37} \mathrm{H}_{45} \mathrm{~N}_{2} \mathrm{Si},[\mathrm{M}+\mathrm{H}]^{+}\right)$, 545.3350 found 545.3347 .<smiles>[3H][SiH](C)CCCCCCCl</smiles>

Bis(6-chlorohexyl)(methyl)silane (5f) 
Following the general procedure II, the title compound was prepared using 6-chlorohexene (160 mg, $1.35 \mathrm{mmol}$ ) and methyldiethoxysilane (201 mg, $1.5 \mathrm{mmol}$ ). The crude product was purified by flash chromatography using hexane as an eluent to afford the title compound (5f) as colorless oil (120 mg, $85 \%)$.

${ }^{1}$ H NMR (400 MHz, $\left.\mathrm{CDCl}_{3}\right) \delta$ 3.77-3.72 (m, 1H), $3.53(\mathrm{t}, \mathrm{J}=6.7 \mathrm{~Hz}, 4 \mathrm{H}), 1.79-1.72(\mathrm{~m}$, 4H), 1.44-1.27 (m, 12H), 0.67-0.57 (m, 4H), 0.03 (d, J = 3.1 Hz, 3H).

${ }^{13}$ C NMR (101 MHz, $\left.\mathrm{CDCl}_{3}\right) \delta 45.3,32.7,32.6,26.7,24.5,12.8,-6.1$.

Elemental analysis: Anal. Calcd for $\mathrm{C}_{13} \mathrm{H}_{28} \mathrm{Cl}_{2} \mathrm{Si}$ : C, 55.10; H, 9.96. Found: C, 55.26 ; H, 10.05 .

$\left(\mathrm{C}_{18} \mathrm{H}_{37}\right)_{2} \mathrm{SiH}_{2}$

\section{Dioctadecylsilane (6a)}

Following the general procedure III, the title compound was prepared using 1-octadecene (378 mg, $1.5 \mathrm{mmol}$ ) and trimethoxysilane (244 mg, $2 \mathrm{mmol}$ ). The crude product was purified by flash chromatography using hexane as an eluent to afford the title compound (6a) as white solid (218 mg, 81\%).

${ }^{1}$ H NMR (400 MHz, $\left.\mathrm{CDCl}_{3}\right) \delta$ 3.64-3.60 (m, 2H), 1.40-1.20 (m, 64H), $0.88(\mathrm{t}, \mathrm{J}=5.8 \mathrm{~Hz}$, $6 \mathrm{H}), 0.71-0.63(\mathrm{~m}, 4 \mathrm{H})$.

${ }^{13}$ C NMR (101 MHz, $\left.\mathrm{CDCl}_{3}\right) \delta$ 33.1, 32.1, 29.86, 29.83, 29.7, 29.53, 29.49, 25.6, 22.9, 14.3, 9.3.

Elemental analysis: Anal. Calcd for $\mathrm{C}_{36} \mathrm{H}_{76} \mathrm{Si}$ : C, 80.51; H, 14.26; Found : C, 80.59 ; H, 14.16.<smiles>CC(C)([SiH3])CCCc1ccccc1</smiles>

\section{Bis(3-phenylpropyl)silane (6b)}

Following the general procedure III, the title compound was prepared using allylbenzene (212 mg, $1.8 \mathrm{mmol}$ ) and trimethoxysilane (244 mg, $2 \mathrm{mmol}$ ). The crude product was purified by flash chromatography using hexane as an eluent to afford the title compound (6b) as colorless oil (95 mg, 71\%).

${ }^{1}$ H NMR (400 MHz, $\mathrm{CDCl}_{3}$ ) $\delta$ 7.29-7.25 (m, 4H), 7.19-7.14 (m, 6H), 3.69-3.64 (m, 2H), 2.64 (t, $J=6.2 \mathrm{~Hz}, 4 \mathrm{H}), 1.74-1.66$ (m, 4H), 0.73-0.69 (m, 4H).

${ }^{13}$ C NMR (101 MHz, $\left.\mathrm{CDCl}_{3}\right) \delta$ 142.4, 128.6, 128.4, 125.9, 39.2, 27.5, 9.0.

HRMS (APPI): calculated for $\left(\mathrm{C}_{18} \mathrm{H}_{23} \mathrm{Si},[\mathrm{M}-\mathrm{H}]^{+}\right)$, 267.1569 found 267.1583. 
<smiles>CCCCCCCCC1CC=CCC1</smiles>

\section{Bis(2-(cyclohex-3-en-1-yl)ethyl)silane (6c)}

Following the general procedure III, the title compound was prepared using 4vinylcyclohexene (162 mg, $1.5 \mathrm{mmol}$ ) and trimethoxysilane (244 mg, $2 \mathrm{mmol}$ ). The crude product was purified by flash chromatography using hexane as an eluent to afford the title compound (6c) as colorless oil (87 mg, 70\%).

${ }^{1}$ H NMR (400 MHz, $\left.\mathrm{CDCl}_{3}\right) \delta$ 5.68-5.61 (m, 4H), 3.69-3.61 (m, 2H), 2.13-1.97 (m, 6H), 1.78-1.75 (m, 2H), 1.66-1.59 (m, 2H), 1.55-1.44 (m, 2H), 1.36-1.28 (m, 4H), 1.21-1.11 (m, 2H), 0.71-0.62 (m, $4 \mathrm{H})$.

${ }^{13}$ C NMR (101 MHz, $\left.\mathrm{CDCl}_{3}\right) \delta$ 127.2, 126.7, 36.3, 32.3, 31.7, 28.6, 25.4, 6.4.

HRMS (APPI): calculated for $\left(\mathrm{C}_{16} \mathrm{H}_{27} \mathrm{Si},[\mathrm{M}-\mathrm{H}]^{+}\right)$, 247.1882 found 247.1891.<smiles>[Y]C(C)(S)CCCCCO[Si](C)(C)C(C)(C)C</smiles>

\section{Bis(tert-butyl((6-(dimethylsilyl)hexyl)oxy)silane (6d)}

Following the general procedure III, the title compound was prepared using tert-butyl(hex-5en-1-yloxy)dimethylsilane (3h) (321 mg, $1.5 \mathrm{mmol}$ ) and trimethoxysilane (244 mg, $2 \mathrm{mmol}$ ). The crude product was purified by flash chromatography using hexane/EtOAc (20:1 to 10:1) as an eluent to afford the title compound (6d) as colorless oil (152 mg, 66\%).

${ }^{1}$ H NMR (400 MHz, $\left.\mathrm{CDCl}_{3}\right) \delta$ 3.63-3.56 (m, 6H), 1.53-1.47 (m, 4H), 1.41-1.30 (m, 12H), 0.89 (s, 18H), 0.70-0.61 (m, 4H), 0.05 (s, 12H).

${ }^{13}$ C NMR (101 MHz, $\left.\mathrm{CDCl}_{3}\right) \delta$ 63.5, 32.9, 32.8, 26.2, 25.6, 25.6, 18.5, 9.3, -5.1.

HRMS (ESI): calculated for $\left(\mathrm{C}_{24} \mathrm{H}_{57} \mathrm{O}_{2} \mathrm{Si}_{3},[\mathrm{M}+\mathrm{H}]^{+}\right), 461.3666$ found 461.3690 .

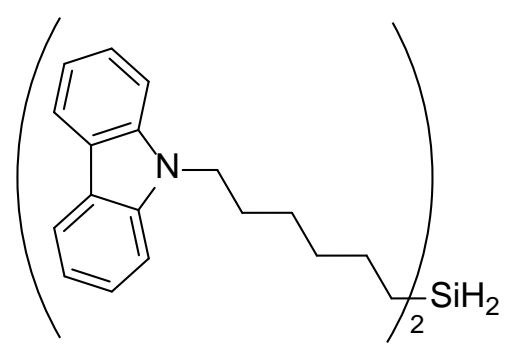

Bis(6-(9H-carbazol-9-yl)hexyl)silane (6e) 
Following the general procedure III, the title compound was prepared using 9-(hex-5-en-1yl)-9H-carbazole (3k) (374 mg, $1.5 \mathrm{mmol}$ ) and trimethoxysilane (244 mg, $2 \mathrm{mmol}$ ). The crude product was purified by flash chromatography using hexane/EtOAc (20:1 to 10:1) as an eluent to afford the title compound (6e) as a yellowish viscous oil (172 mg, 65\%).

${ }^{1}$ H NMR (400 MHz, $\left.\mathrm{CDCl}_{3}\right) \delta 8.17(\mathrm{~d}, \mathrm{~J}=7.8 \mathrm{~Hz}, 4 \mathrm{H}), 7.52(\mathrm{~m}, 4 \mathrm{H}), 7.44$ (d, J = $8.1 \mathrm{~Hz}$, 4H), 7.30 (m, 4H), 4.32 (t, J = 7.1 Hz, 4H), 3.69-3.63 (m, 2H), 1.95-1.86 (m, 4H), 1.46-1.35 (m, 12H), 0.71-0.63 (m, 4H).

${ }^{13}$ C NMR $\left(101 \mathrm{MHz}, \mathrm{CDCl}_{3}\right) \delta 140.5,125.7,122.9,120.5,118.8,108.8,43.1,32.7,29.0$, 27.0, 25.4, 9.2.

HRMS (ESI): calculated for $\left(\mathrm{C}_{36} \mathrm{H}_{43} \mathrm{~N}_{2} \mathrm{Si},[\mathrm{M}+\mathrm{H}]^{+}\right)$, 531.3190 found 531.3196 .<smiles>CC(C)(S)CCCCCCl</smiles>

\section{Bis(6-chlorohexyl)silane (6f)}

Following the general procedure III, the title compound was prepared using 6-chlorohexene (142 mg, $1.2 \mathrm{mmol}$ ) and trimethoxysilane (244 mg, $2 \mathrm{mmol}$ ). The crude product was purified by flash chromatography using hexane as an eluent to afford the title compound (6f) as a colorless oil (65 mg, 48\%).

${ }^{1}$ H NMR (400 MHz, $\left.\mathrm{CDCl}_{3}\right) \delta$ 3.68-3.61 (m, 2H), $3.53(\mathrm{t}, \mathrm{J}=6.6 \mathrm{~Hz}, 4 \mathrm{H}), 1.80-1.73(\mathrm{~m}$, 4H), 1.45-1.30 (m, 12H), 0.72-0.64 (m, 4H).

${ }^{13}$ C NMR (101 MHz, $\left.\mathrm{CDCl}_{3}\right) \delta$ 45.2, 32.7, 32.2, 26.7, 25.4, 9.2.

HRMS (APPI): calculated for $\left(\mathrm{C}_{12} \mathrm{H}_{25} \mathrm{Cl}_{2} \mathrm{Si},[\mathrm{M}-\mathrm{H}]{ }^{+}\right)$, 267.1102 found 267.1097.<smiles>CCCCCCCC[SiH](C)CCC1CC=CCC1</smiles>

\section{(2-(Cyclohex-3-en-1-yl)ethyl)(methyl)(octyl)silane (7a)}

In a nitrogen filled glovebox, an oven-dried $30 \mathrm{~mL}$ re-sealable screw-cap vial equipped with a Teflon coated magnetic stirring bar was charged with methyldiethoxysilane (2b) (1.65 mmol) and dry THF (2 mL). An aliquot of the stock solution of complex 1a and $\mathrm{NaO}_{\mathrm{t}} \mathrm{Bu}(2.0$ $\mathrm{mL}$, corresponding to $5 \mathrm{~mol} \%$ of Ni catalyst) was added. After that, 1-octene (56 mg, 0.5 $\mathrm{mmol}$ ) in $1 \mathrm{~mL}$ of THF was added and the resulting mixture was stirred at room temperature for 2 hours. The vial was opened, 4-vinylcyclohex-1-ene (108 mg, $1.0 \mathrm{mmol}$ ) was added and mixture was stired overnight. The reaction mixture was concentrated under vacuum. The 
residue was purified by chromatography using hexane as an eluent to afford $\mathbf{7 a}$ as colorless oil (90 mg, 68\%).

${ }^{1}$ H NMR (400 MHz, $\left.\mathrm{CDCl}_{3}\right) \delta$ 5.68-5.64 (m, 2H), 3.81-3.75 (m, 1H), 2.15-2.05 (m, 3H), 1.78-1.76 (m, 1H), 1.65-1.60 (m, 1H), 1.48-1.46 (m, 1H), 1.36-1.22 (m, 15H), 0.89 (t, $J=6.2$ $\mathrm{Hz}, 3 \mathrm{H}), 0.68-0.54$ (m, 4H), 0.05 (d, $J=3.6 \mathrm{~Hz}, 3 \mathrm{H})$.

${ }^{13} \mathbf{C}$ NMR $\left(101 \mathrm{MHz}, \mathrm{CDCl}_{3}\right) \delta 127.2,126.8,36.5,33.5,32.1,31.8,31.5,29.5,29.4,28.7$, 25.5, 24.7, 22.9, 14.3, 12.9, 9.9, -6.1.

Elemental analysis: Anal. Calcd for $\mathrm{C}_{17} \mathrm{H}_{34} \mathrm{Si}$ : C, 76.61; H, 12.86; Found : C, 76.43 ; H, 12.97.<smiles>CCCCCCCC[SH+][SH2+]</smiles>

\section{Octyldiphenylsilane (8a)}

Title compound was prepared using diphenylsilane (110 mg, $0.6 \mathrm{mmol})$ and 1-octene (56 mg) in $96 \%$ yield. (142 mg)

${ }^{1}$ H NMR $\left(400 \mathrm{MHz}, \mathrm{CDCl}_{3}\right) \delta$ 7.55-7.51 (m, 4H), 7.41- $7.33(\mathrm{~m}, 6 \mathrm{H}), 4.84(\mathrm{t}, J=3.7 \mathrm{~Hz}$, 1H,), 1.47- 1.42 (m, 2H), 1.37- 1.34 (m, 2H), 1.27- 1.23 (m, 8H,), 1.16 - 1.11 (m, 2H), 0.86 (t, $J=6.7 \mathrm{~Hz}, 3 \mathrm{H})$.

${ }^{13}$ C NMR (101 MHz, $\left.\mathrm{CDCl}_{3}\right) \delta$ 135.2, 134.8, 129.5, 128.1, 33.3, 32.0, 29.4, 29.3, 24.5, 22.8, 14.3, 12.3. The spectroscopic data corresponds to that previously reported. ${ }^{9}$

\section{$\mathbf{E t}_{2}$ (nOct)SiH}

\section{Diethyloctylsilane (8b)}

Title compound was prepared using diethylsilane (53 $\mathrm{mg}, 0.6 \mathrm{mmol})$ and 1-octene (56 mg) in $93 \%$ yield. (93 $\mathrm{mg}$ )

${ }^{1}$ H NMR (400 MHz, $\left.\mathrm{CDCl}_{3}\right) \delta$ 3.66-3.56 (m, 1H), 1.31-1.26 (m, 12H), $0.97(\mathrm{t}, \mathrm{J}=7.7 \mathrm{~Hz}$, $6 \mathrm{H}), 0.88(\mathrm{t}, \mathrm{J}=5.0 \mathrm{~Hz}, 3 \mathrm{H}), 0.59-0.57(\mathrm{~m}, 6 \mathrm{H})$.

${ }^{13}$ C NMR (101 MHz, $\left.\mathrm{CDCl}_{3}\right) \delta$ 33.6, 32.1, 29.5, 29.4, 24.8, 23.0, 14.3, 10.8, 8.4, 3.0.

The spectroscopic data corresponds to that previously reported. ${ }^{10}$ 


\section{Unreactive substrates for Ni-catalyzed hydrosilylation}

Listed below are the substrates which didn't provide or provided only trace amount of desired hydrosilylation products using conditions of Scheme 2.<smiles>C=C(C)c1ccccc1</smiles>
a-methylstyrene<smiles>C=CCOCCBr</smiles>$$
\text { a-methylstyrene }
$$<smiles>C=CCN(C)CCN</smiles>

$N^{\prime} N$-dimethylallylamine

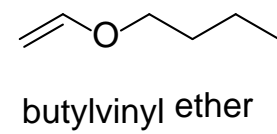

butylvinyl ether<smiles>C=C[N]</smiles>

acrylonitrile<smiles>C=CCOc1ccc(Br)cc1</smiles>

1-(allyloxy)-4-bromobenzene<smiles>C=CCCCN1C(=O)c2ccccc2C1=O</smiles>

2-(hex-5-en-1-yl)isoindoline-1,3-dione<smiles>C=CCCCCCCCCCC(=O)N(C)C</smiles>

$N^{\prime} N$-dimethyldodec-11-enamide

Fig. S13. Unreactive hydrosilylation substrates. 


\section{References}

(1) Florence, G. J.; Fraser, A. L.; Gould, E. R.; King, E. F. B.; Menzies, S. K.; Morris, J. C.; Tulloch, L. B.; Smith, T. K. ChemMedChem 2014, 9, 25482556.

(2) Schleicher, K. D.; Jamison, T. F. Org. Lett. 2007, 9, 875-878.

(3) Nishida, A.; Kawahara, N.; Nishida, M.; Yonemitsu, O. Tetrahedron 1996, 52, 9713-9734.

(4) Paquette, L. A.; Leone-Bay, A. J. Am. Chem. Soc. 1983, 105, 7352-7358.

(5) Kieltsch, I.; Dubinina, G. G.; Hamacher, C.; Kaiser, A.; Torres-Nieto, J.; Hutchison, J. M.; Klein, A.; Budnikova, Y.; Vicic, D. A. Organometallics 2010, 29, 1451-1456.

(6) He, J.; Liu, Z.; Du, G.; Fu, Y.; Zhang, S.; Li, X. Organometallics 2014, 33, 6103-6112.

(7) Csok, Z.; Vechorkin, O.; Harkins, S. B.; Scopelliti, R.; Hu, X. J. Am. Chem. Soc. 2008, 130, 8156-8157.

(8) Pérez García, P. M.; Ren, P.; Scopelliti, R.; Hu, X. ACS Catalysis 2015, 5, 1164-1171.

(9) Kamata, K.; Suzuki, A.; Nakai, Y.; Nakazawa, H. Organometallics 2012, 31, 3825-3828.

(10) Srinivas, V.; Nakajima, Y.; Ando, W.; Sato, K.; Shimada, S. Catal. Sci. Technol. 2015, 5, 2081-2084. 

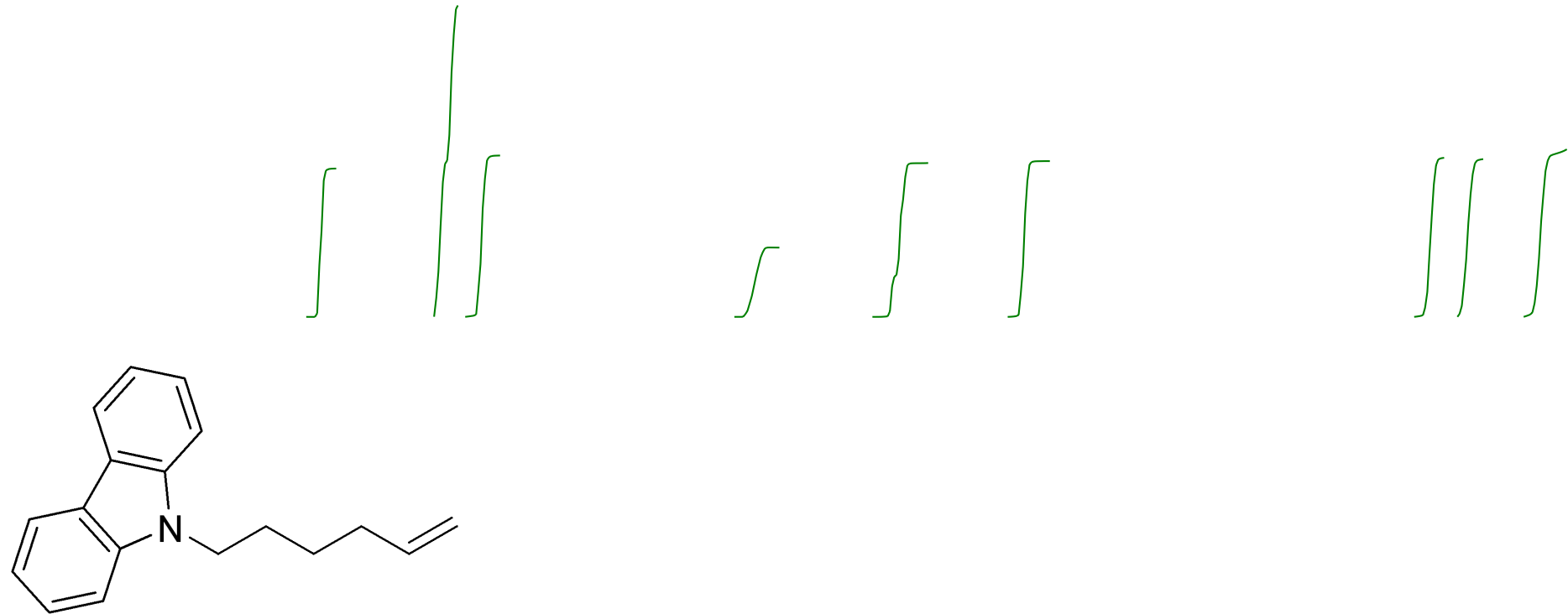

9-(hex-5-en-1-yl)-9H-carbazole (3k)

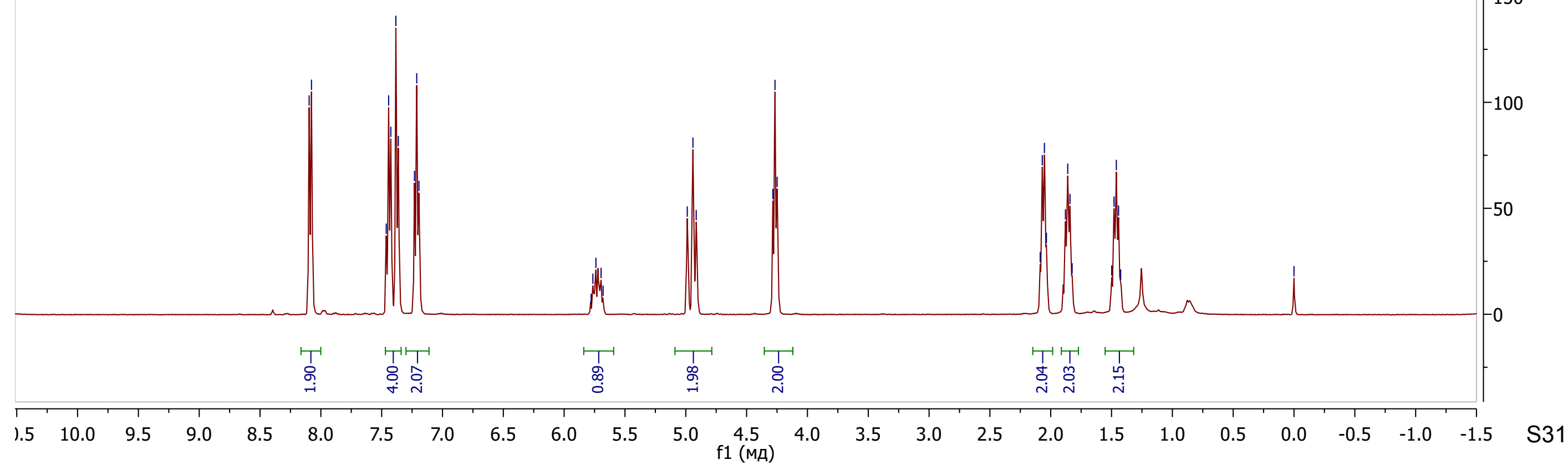




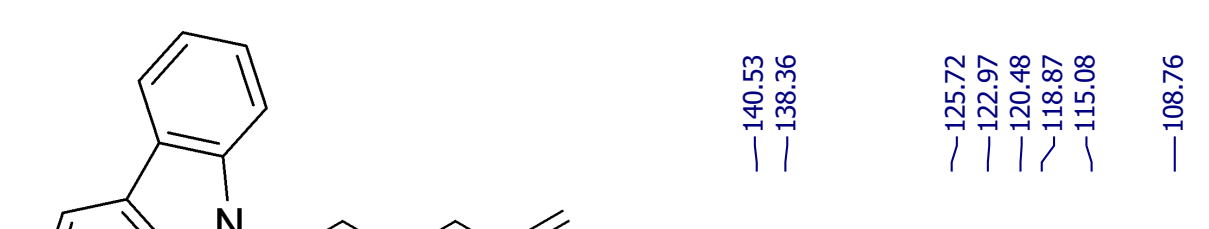

9-(hex-5-en-1-yl)-9H-carbazole (3k) 

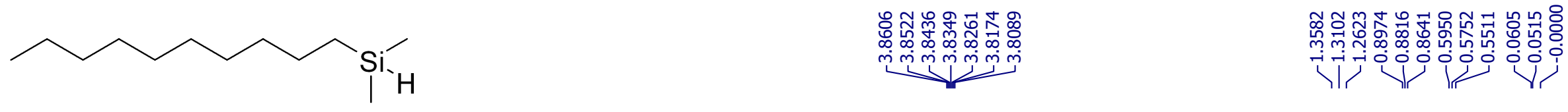

Dimethyl(decyl)silane (4a)

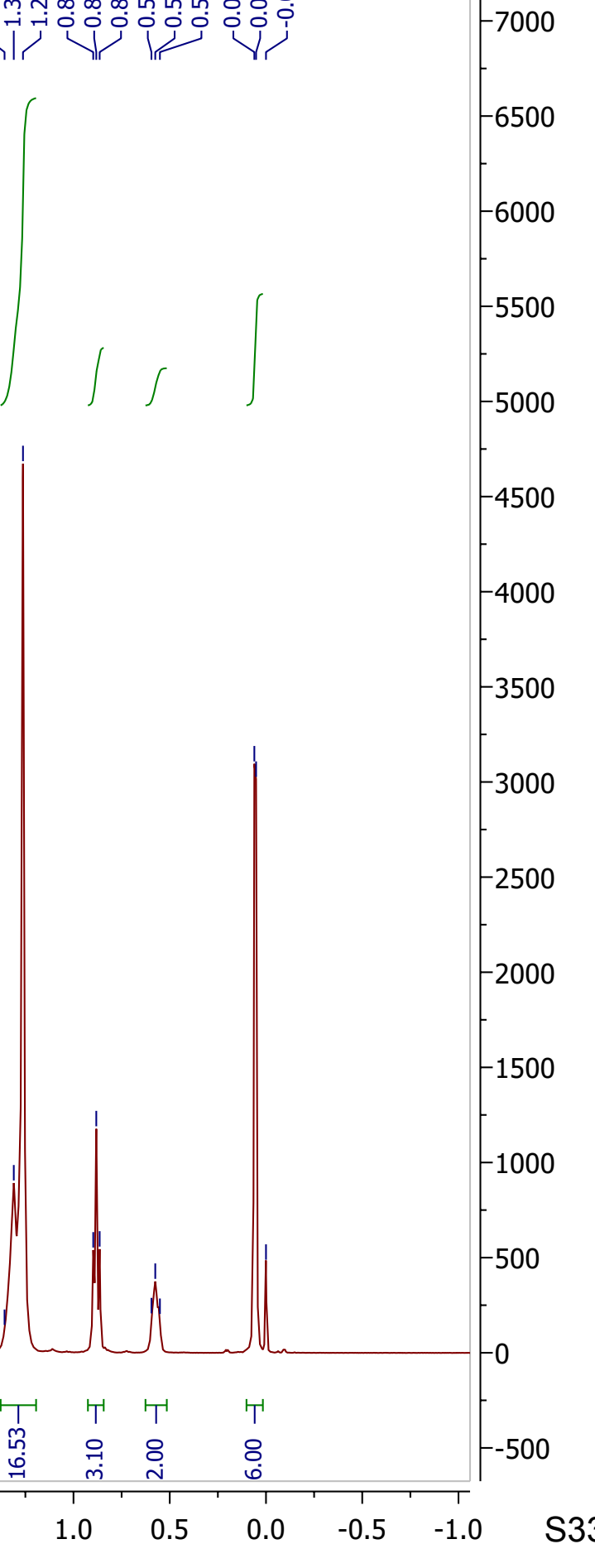




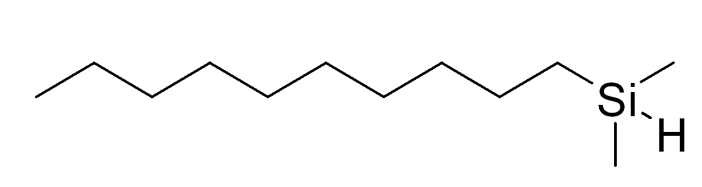

Dimethyl(decyl)silane (4a) 
$\mathrm{C}_{18} \mathrm{H}_{37}-\stackrel{\mathrm{SiH}}{\mid}$

Dimethyl(octadecyl)silane (4b) 
$\mathrm{C}_{18} \mathrm{H}_{37}-\stackrel{\mid}{\mathrm{SiH}}$

Dimethyl(octadecyl)silane (4b) 


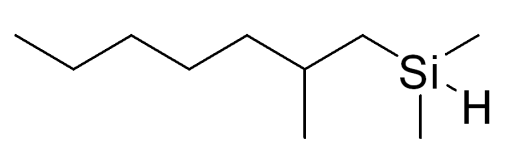

Dimethyl(2-methylheptyl)silane (4c)

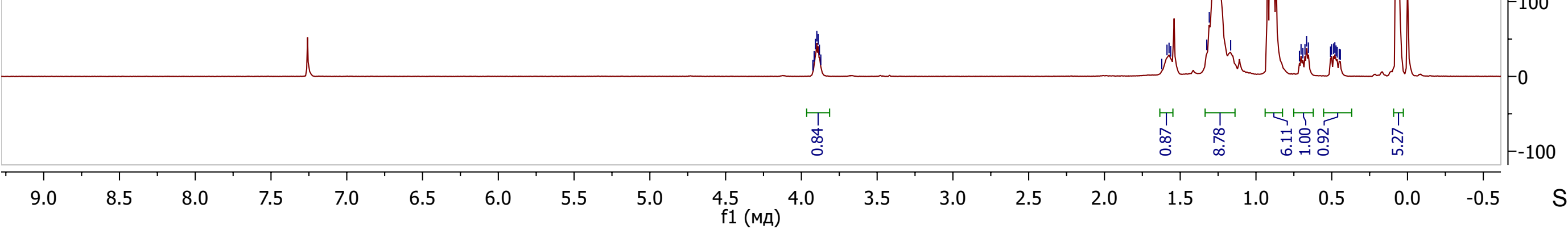




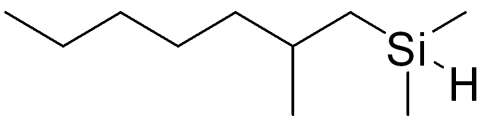

Dimethyl(2-methylheptyl)silane (4c) 


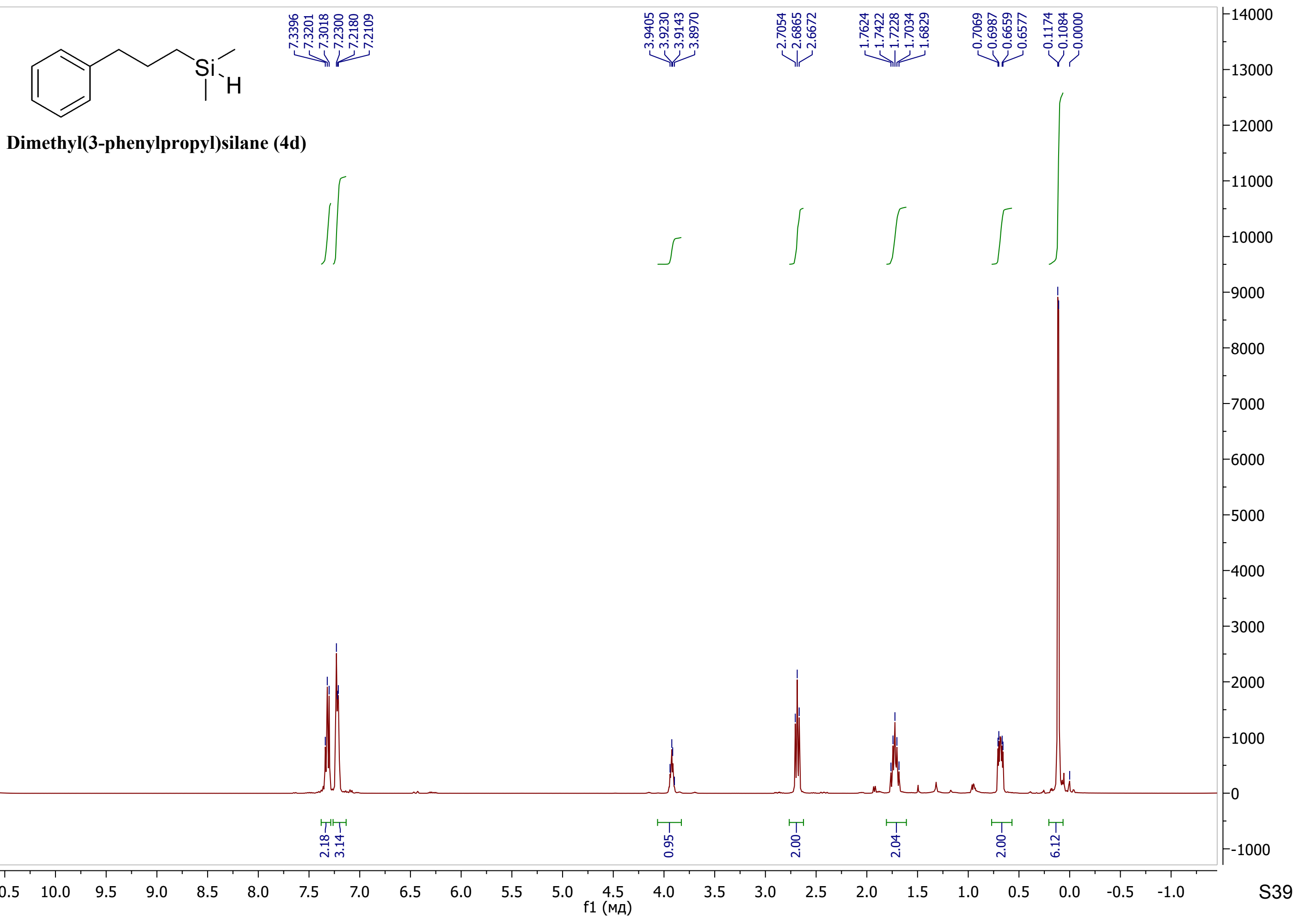




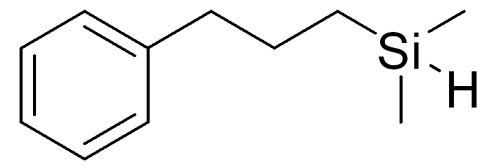

\section{Dimethyl(3-phenylpropyl)silane (4d)}



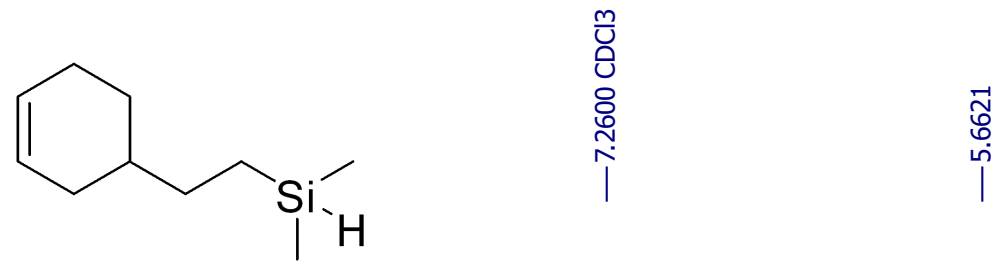

\section{(2-(Cyclohex-3-en-1-yl)ethyl)dimethylsilane (4e)}

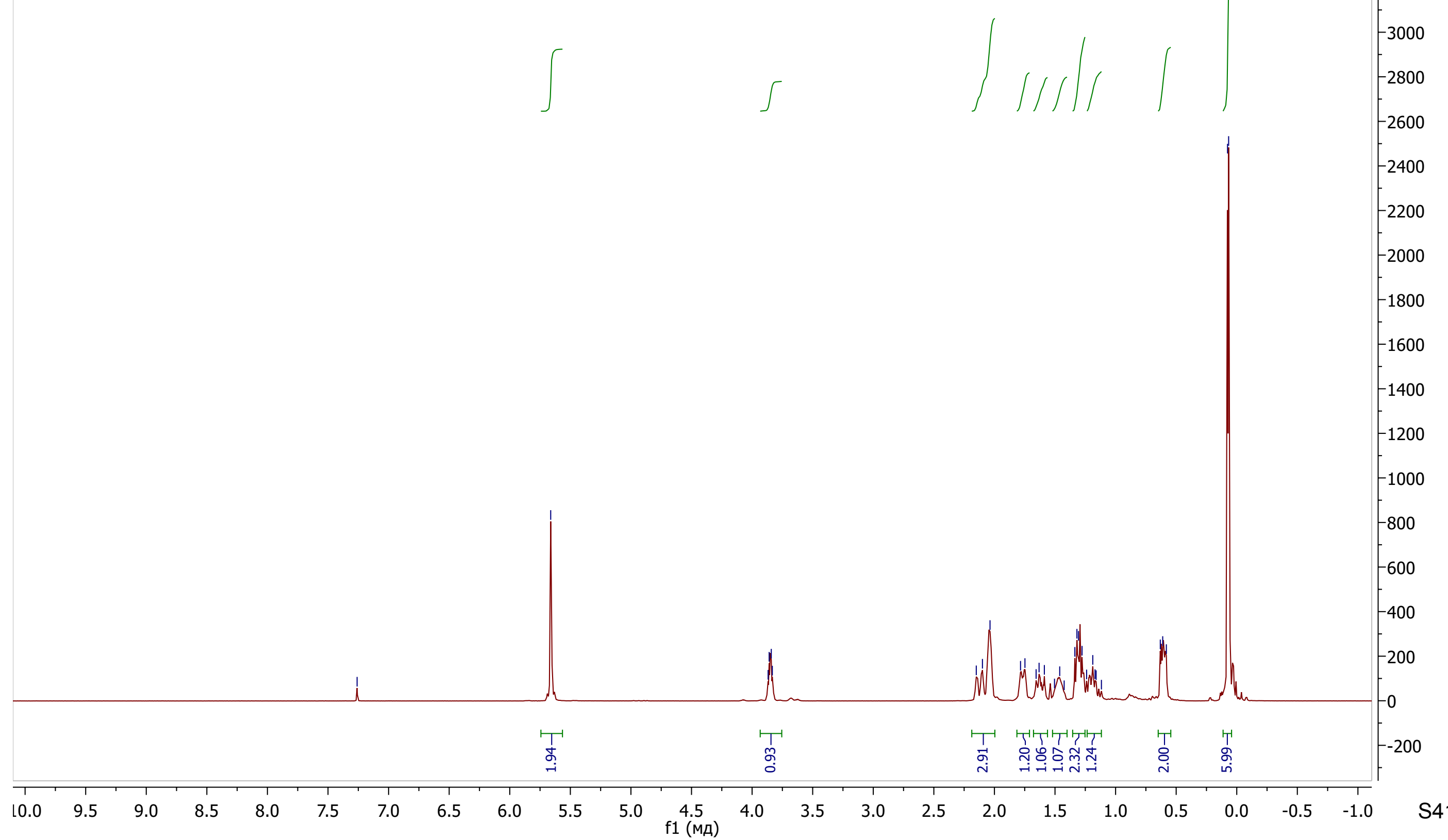




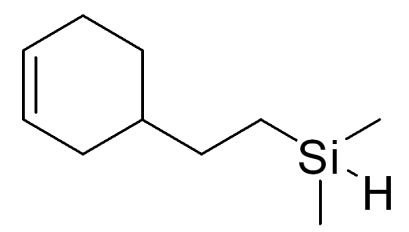

(2-(Cyclohex-3-en-1-yl)ethyl)dimethylsilane (4e) 


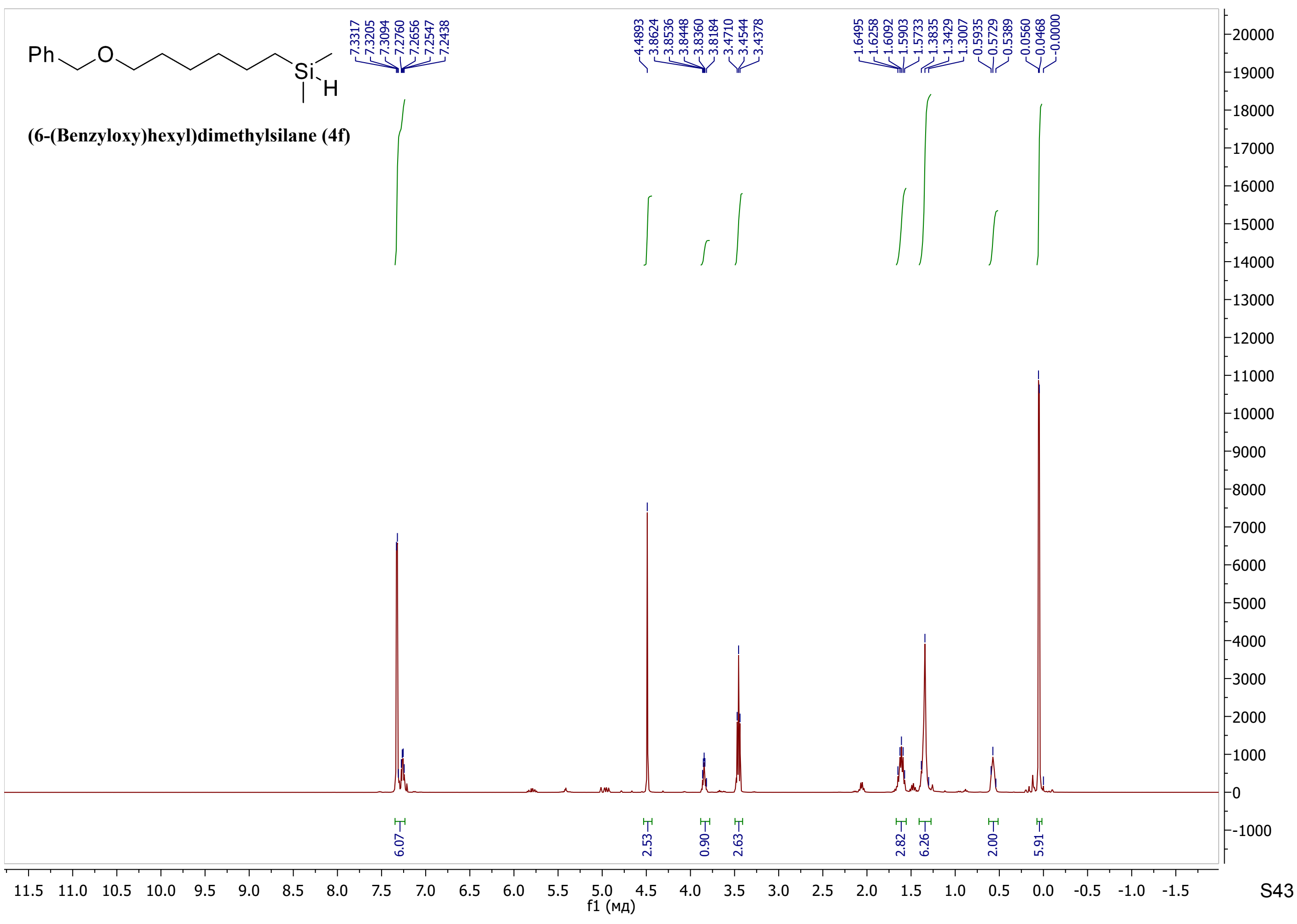




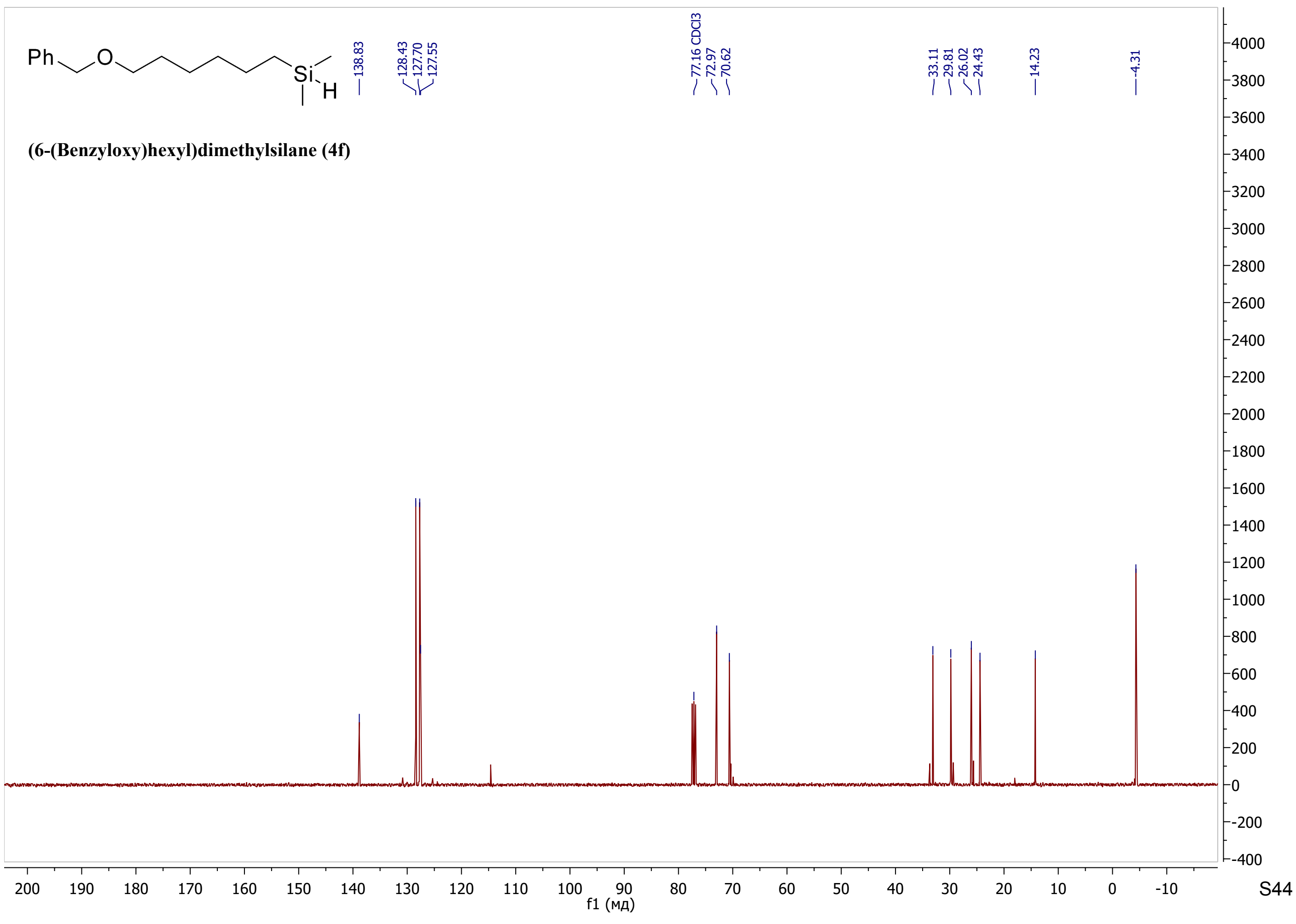




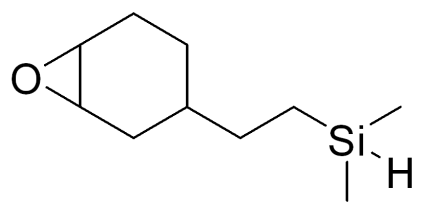

\section{(2-(7-Oxabicyclo[4.1.0]heptan-3-yl)ethyl)dimethylsilane ( mixture of isomers) (4g)}

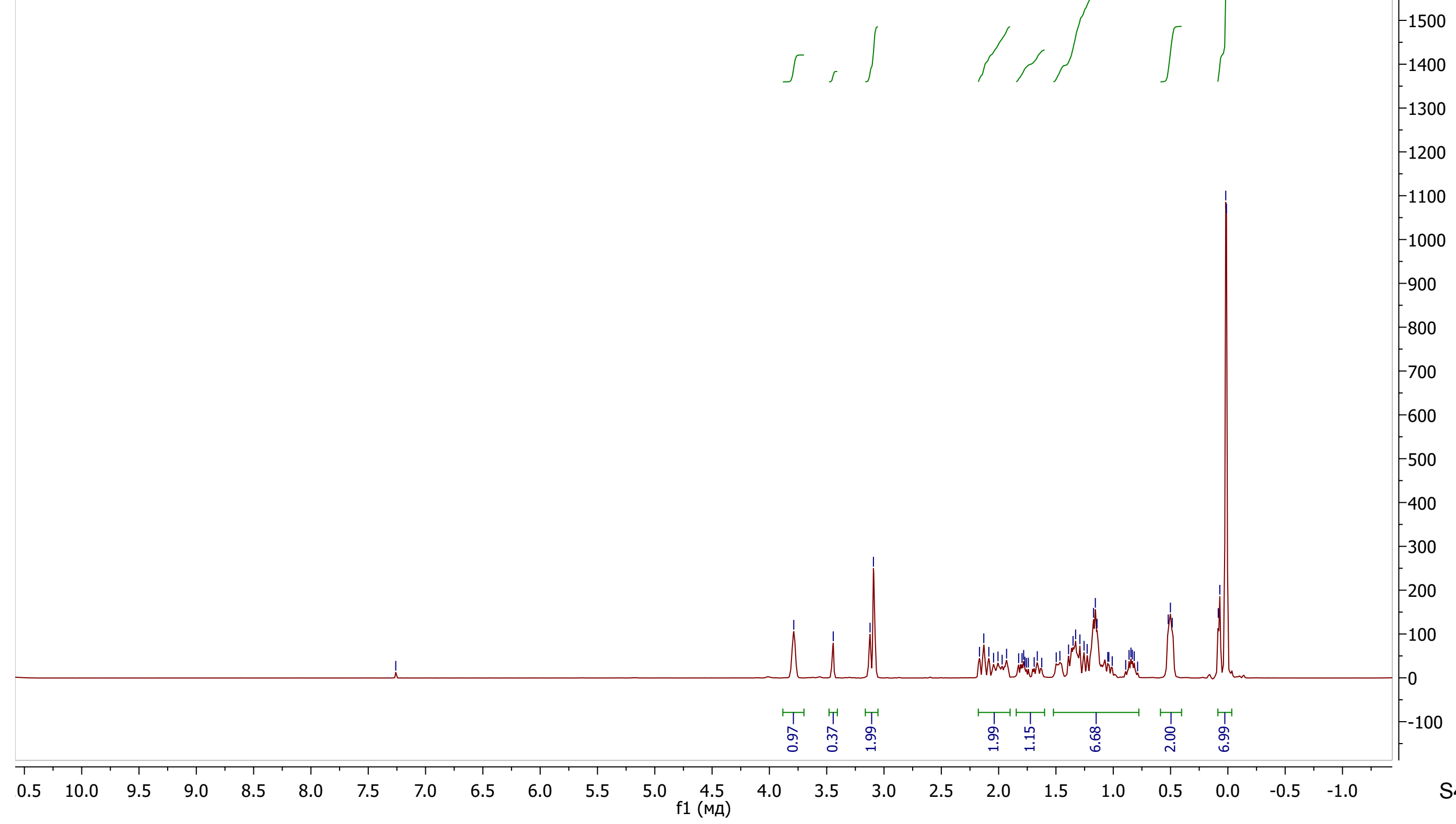




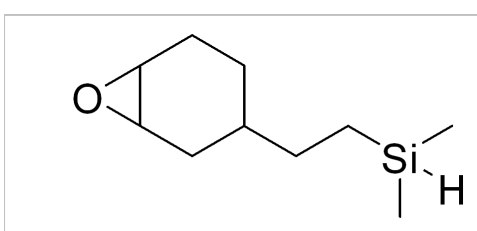

(2-(7-Oxabicyclo[4.1.0]heptan-3-yl)ethyl)dimethylsilane ( mixture of isomers) (4g)

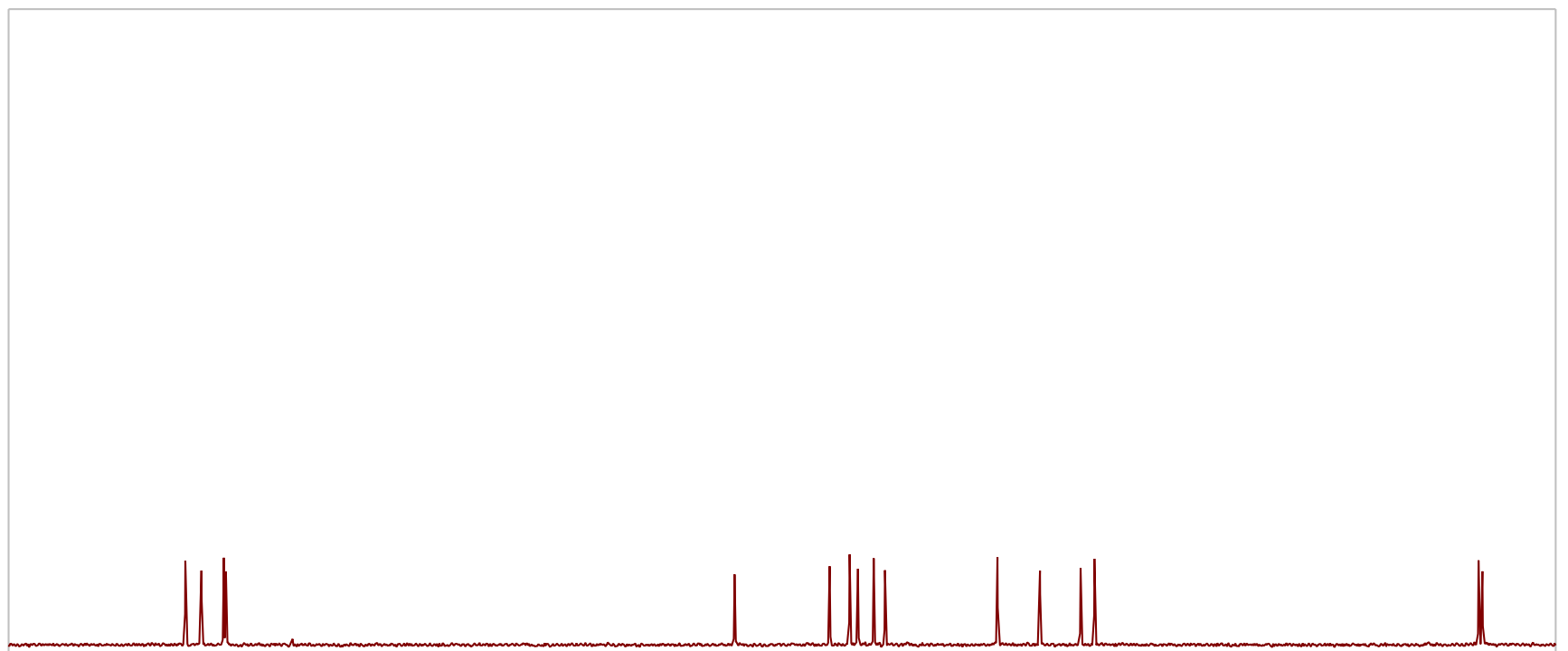




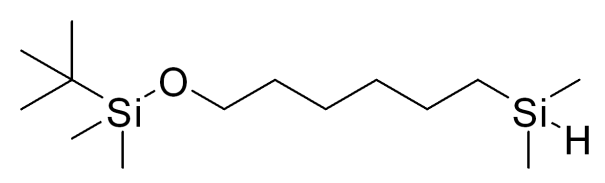

Tert-butyl((6-(dimethylsilyl)hexyl)oxy)dimethylsilane (4h)

1

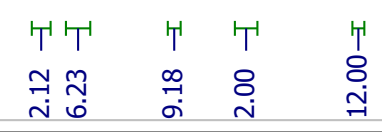$$
\text { ำ ำ }
$$

$\frac{\sim}{1}$

1.0

0.5

0.0



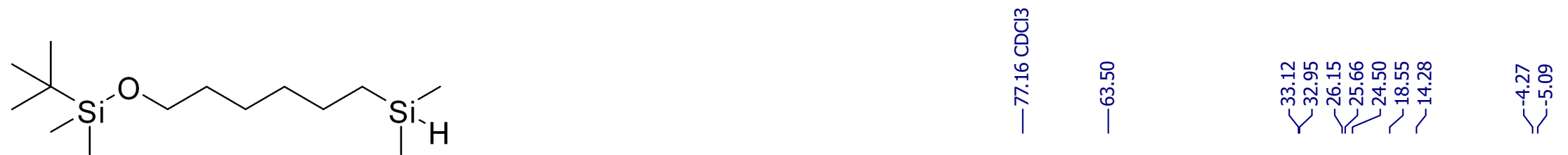

Tert-butyl((6-(dimethylsilyl)hexyl)oxy)dimethylsilane (4h) 


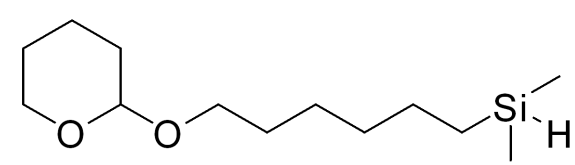

Dimethyl(6-((tetrahydro-2H-pyran-2-yl)oxy)hexyl)silane (4i)
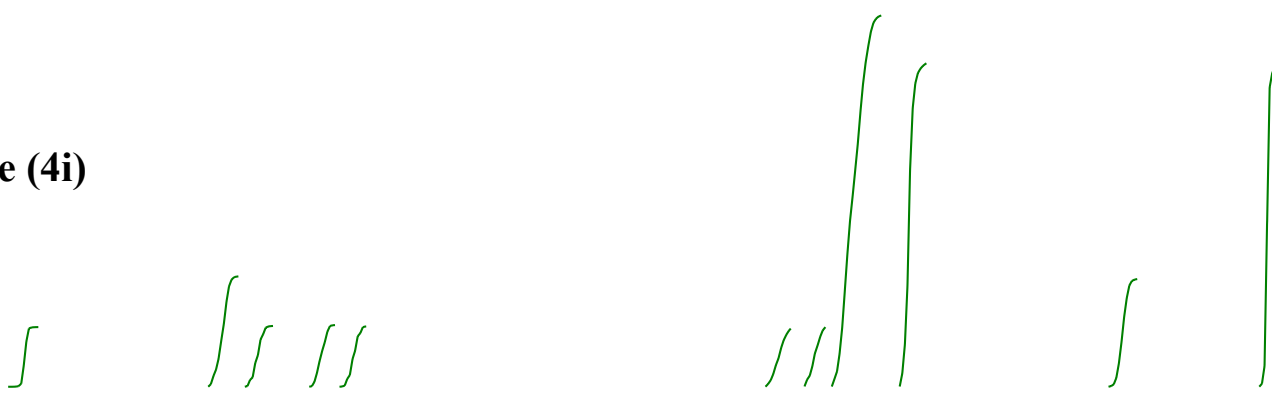

(1.0




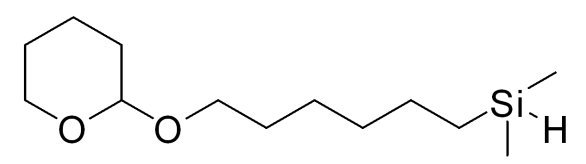

Dimethyl(6-((tetrahydro-2H-pyran-2-yl)oxy)hexyl)silane (4i)

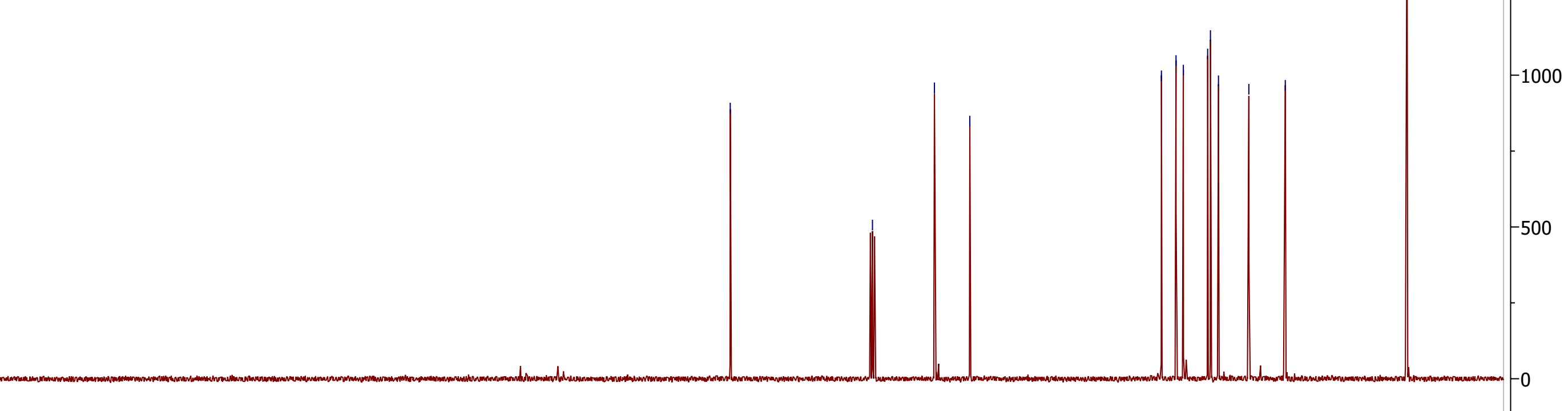


10-(chlorodecyl)dimethylsilane $(4 \mathbf{j})$

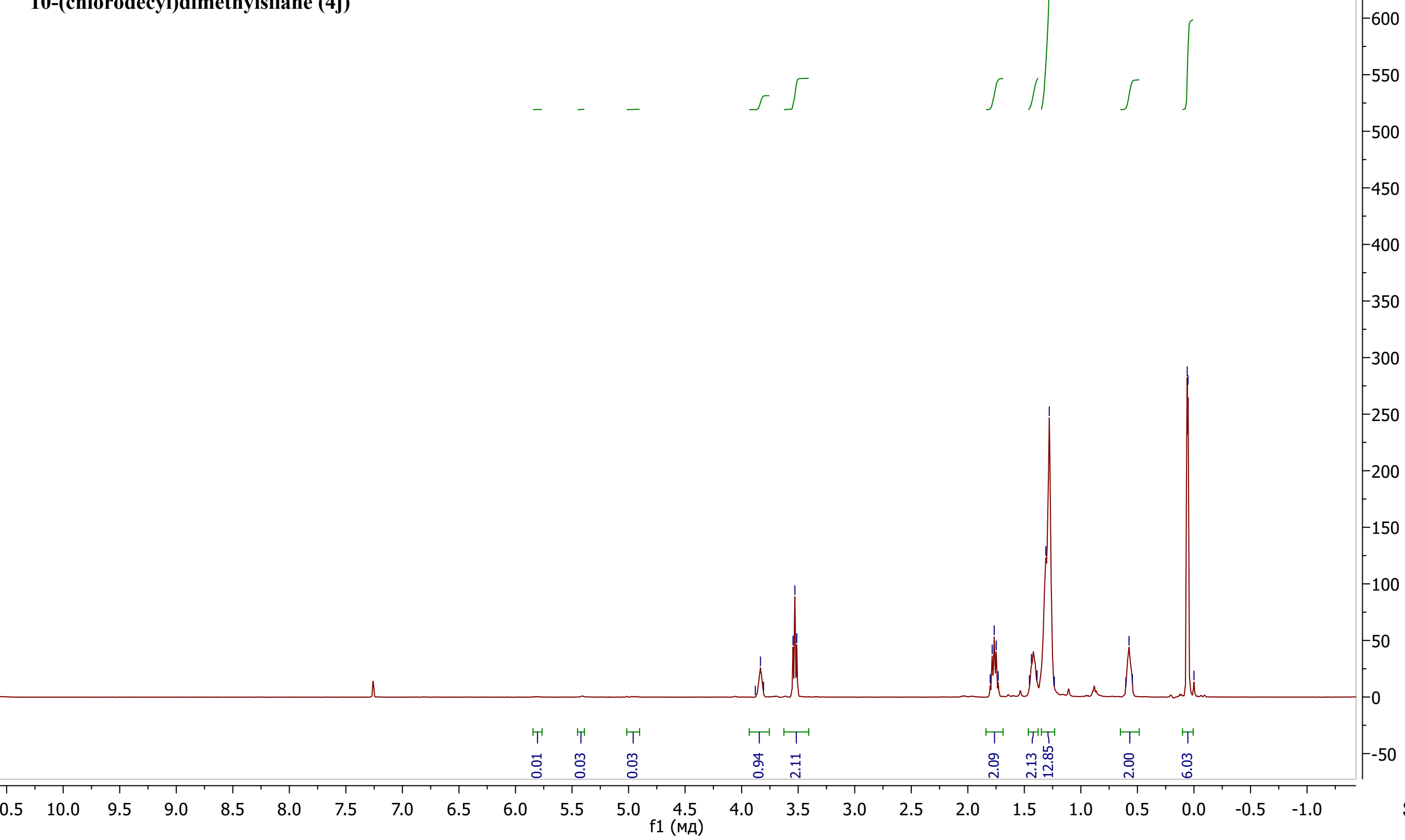




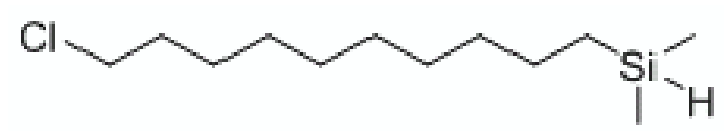

10-(chlorodecyl)dimethylsilane (4j) 


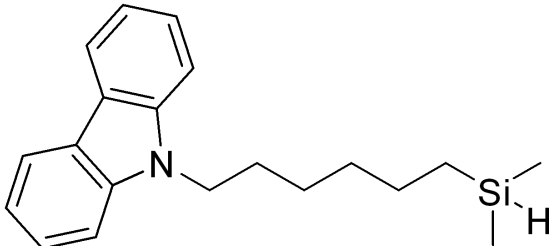

9-(6-(Dimethylsilyl)hexyl)-9H-carbazole (4k) 


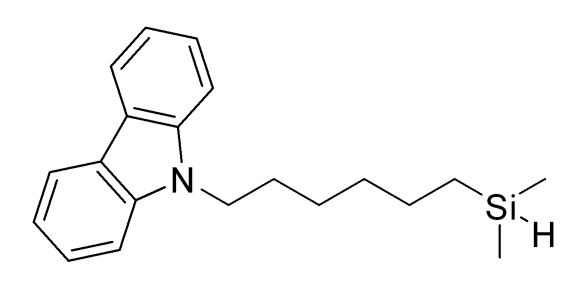

9-(6-(Dimethylsilyl)hexyl)-9H-carbazole (4k) 


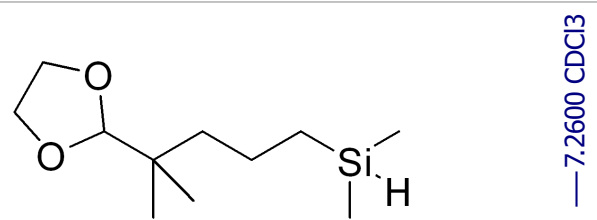

(4-(1,3-Dioxolan-2-yl)-4-methylpentyl)dimethylsilane (4l)
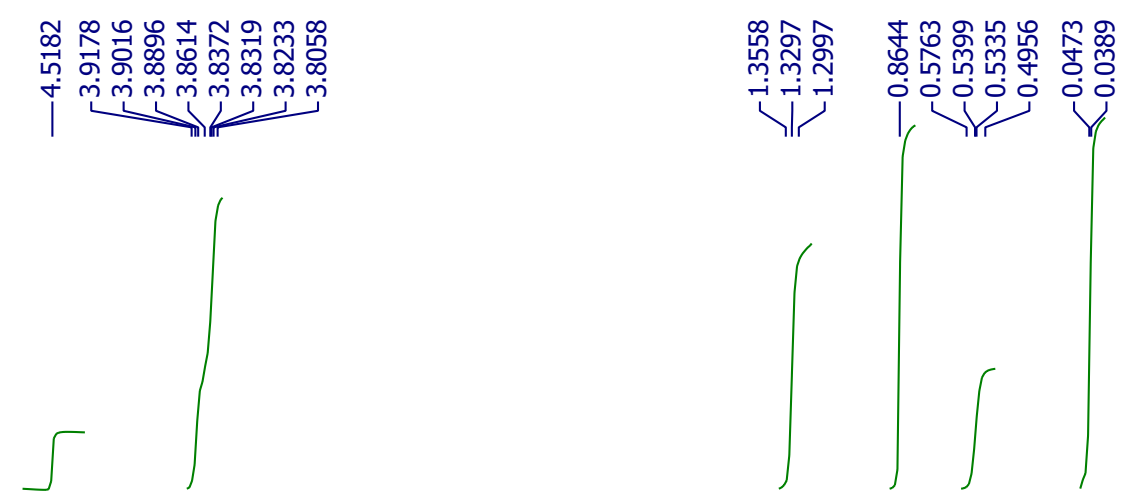

$-21000$
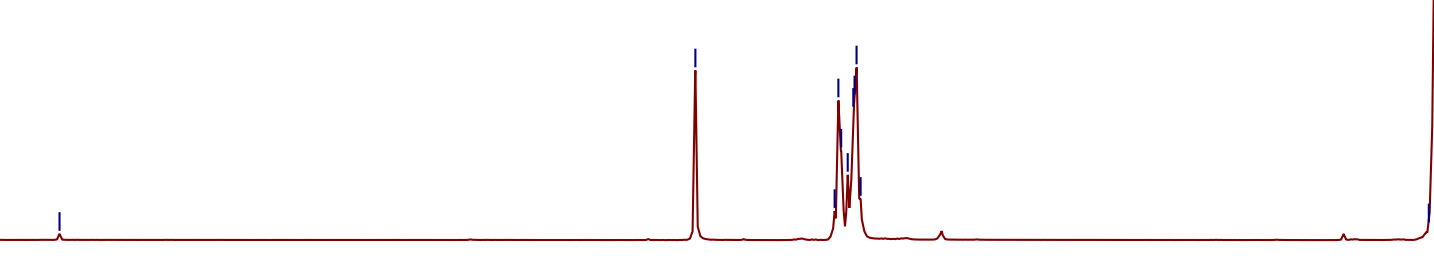


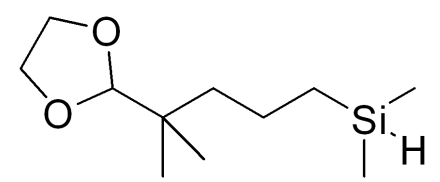

(4-(1,3-Dioxolan-2-yl)-4-methylpentyl)dimethylsilane (4l) 


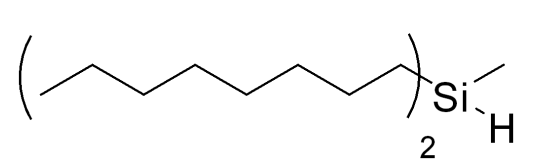

Methyldioctylsilane (5a)

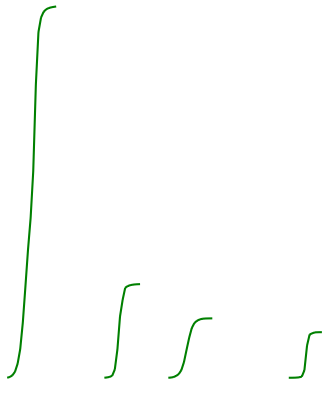




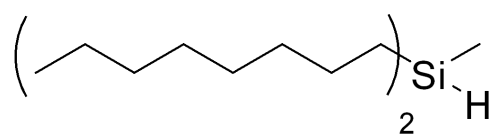

Methyldioctylsilane (5a) 


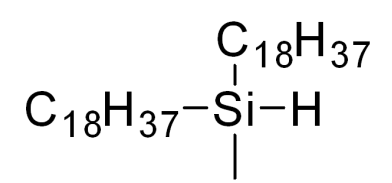

Methyldioctadecylsilane (5b) 


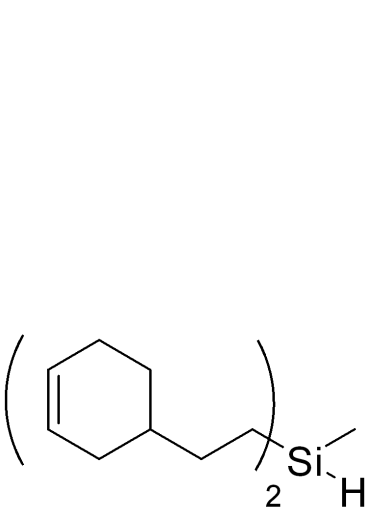<smiles>C1CC1</smiles>

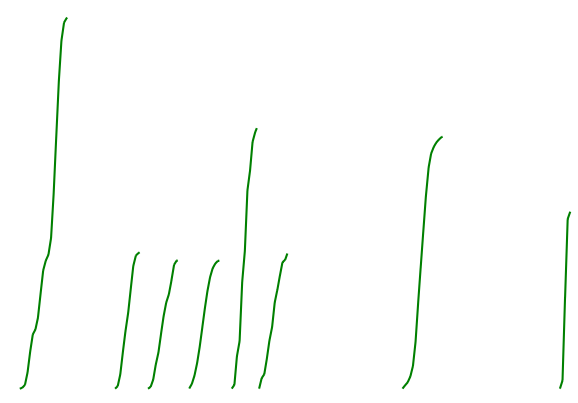

Bis(2-(cyclohex-3-en-1-yl)ethyl)(methyl)silane (5c)

$\begin{array}{llllll}6.5 & 6.0 & 5.5 & 5.0 & 4.5 & \begin{array}{c}4.0 \\ \mathrm{f} 1(\mathrm{Mд})\end{array}\end{array}$

$3.5 \quad 3.0$




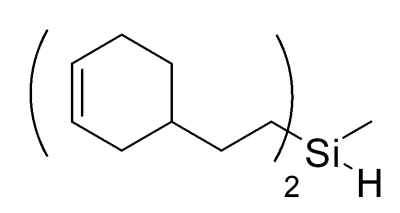

Bis(2-(cyclohex-3-en-1-yl)ethyl)(methyl)silane (5c) 


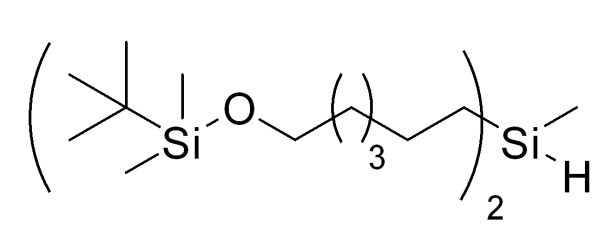

\section{Bis(tert-butyl((6-(dimethylsilyl)hexyl)oxy)(methyl)silane (5d)}

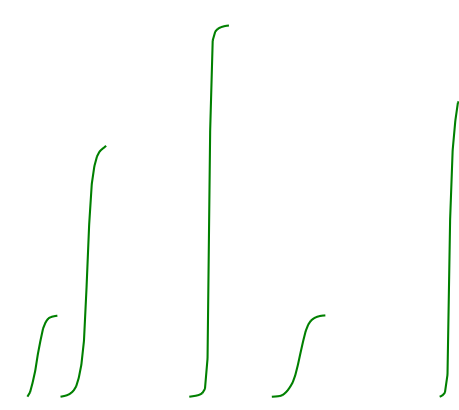

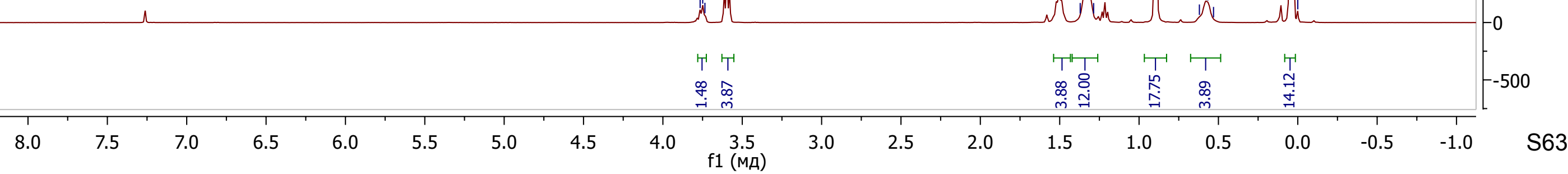



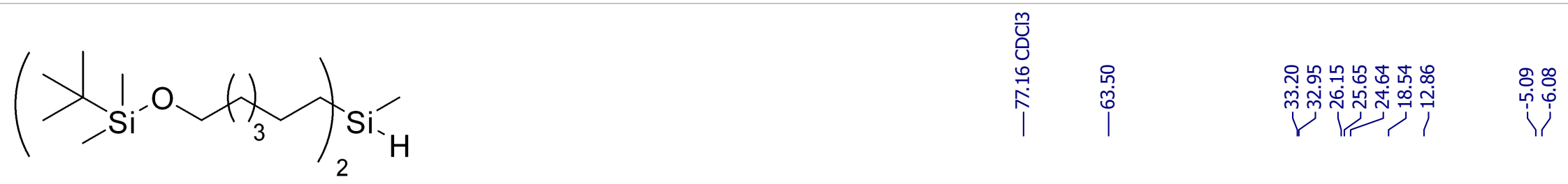

Bis(tert-butyl((6-(dimethylsilyl)hexyl)oxy)(methyl)silane (5d) 


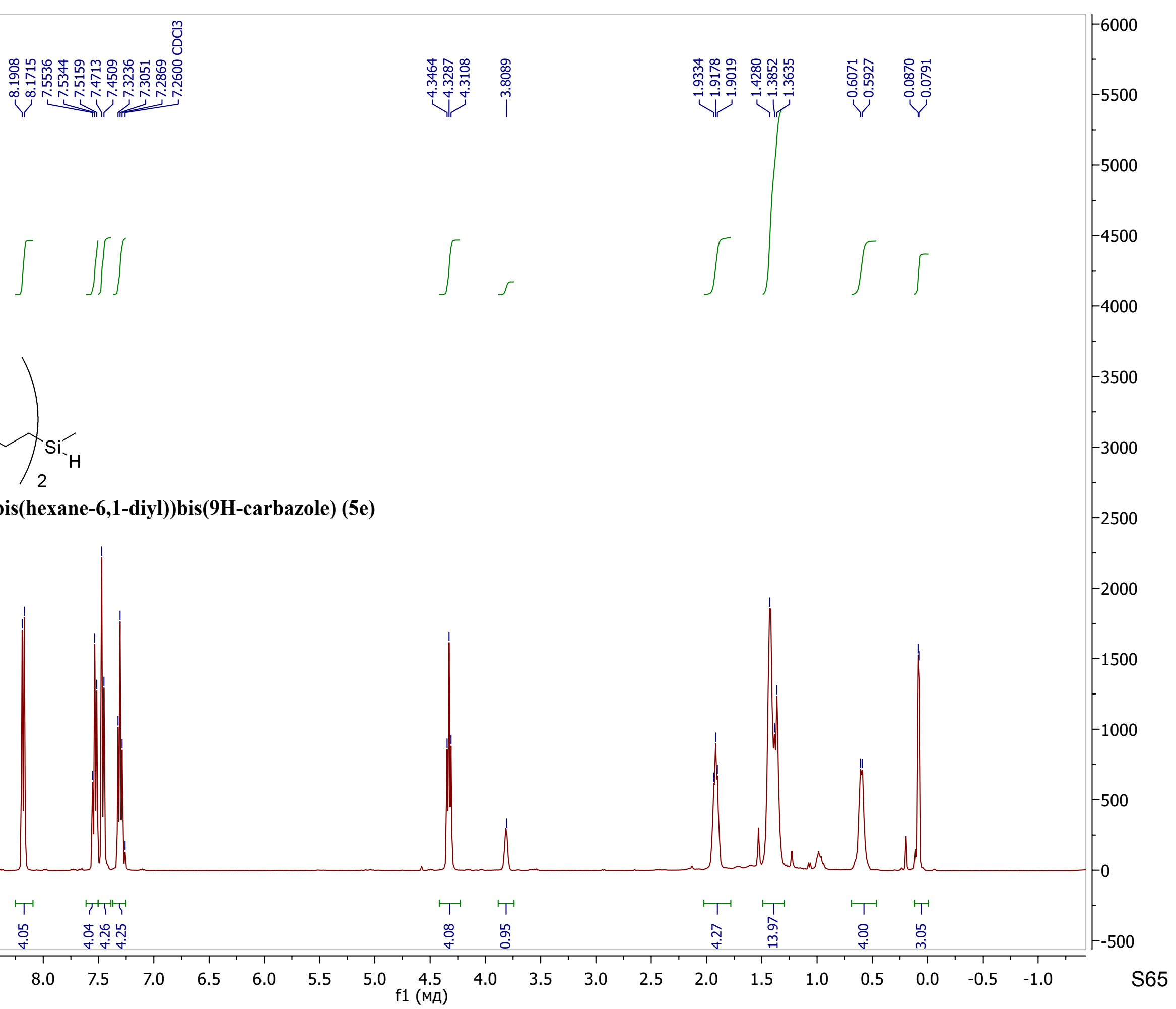




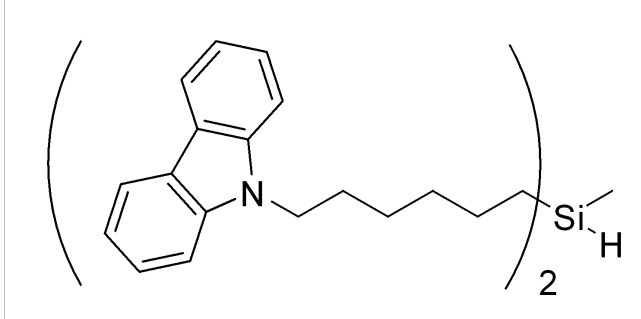

9,9'-((Methylsilanediyl)bis(hexane-6,1-diyl))bis(9H-carbazole) (5e) 


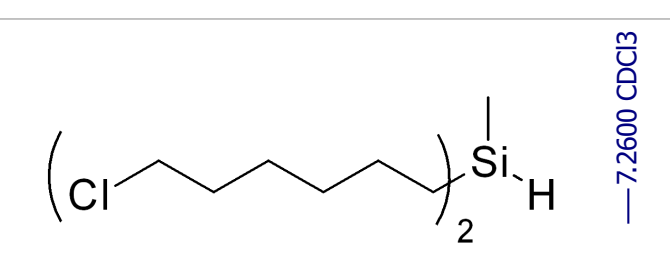

Bis(6-chlorohexyl)(methyl)silane (5f)

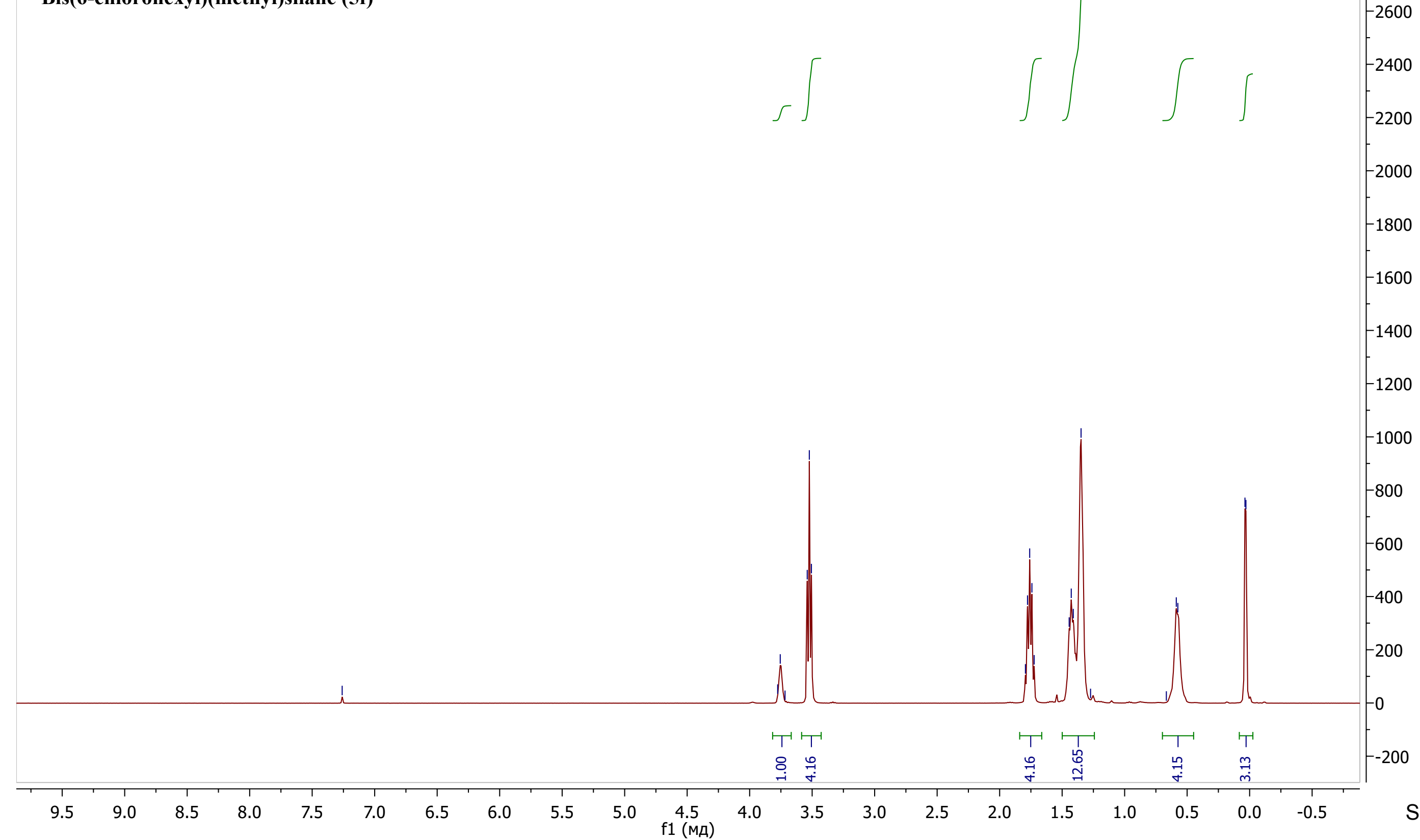




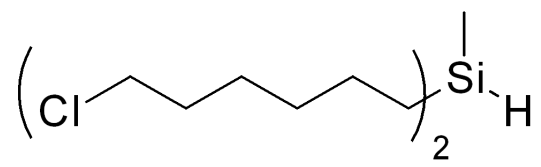

Bis(6-chlorohexyl)(methyl)silane (5f) 


\section{$\left(\mathrm{C}_{18} \mathrm{H}_{37}\right)_{2} \mathrm{SiH}_{2}$}

Dioctadecylsilane (6a)

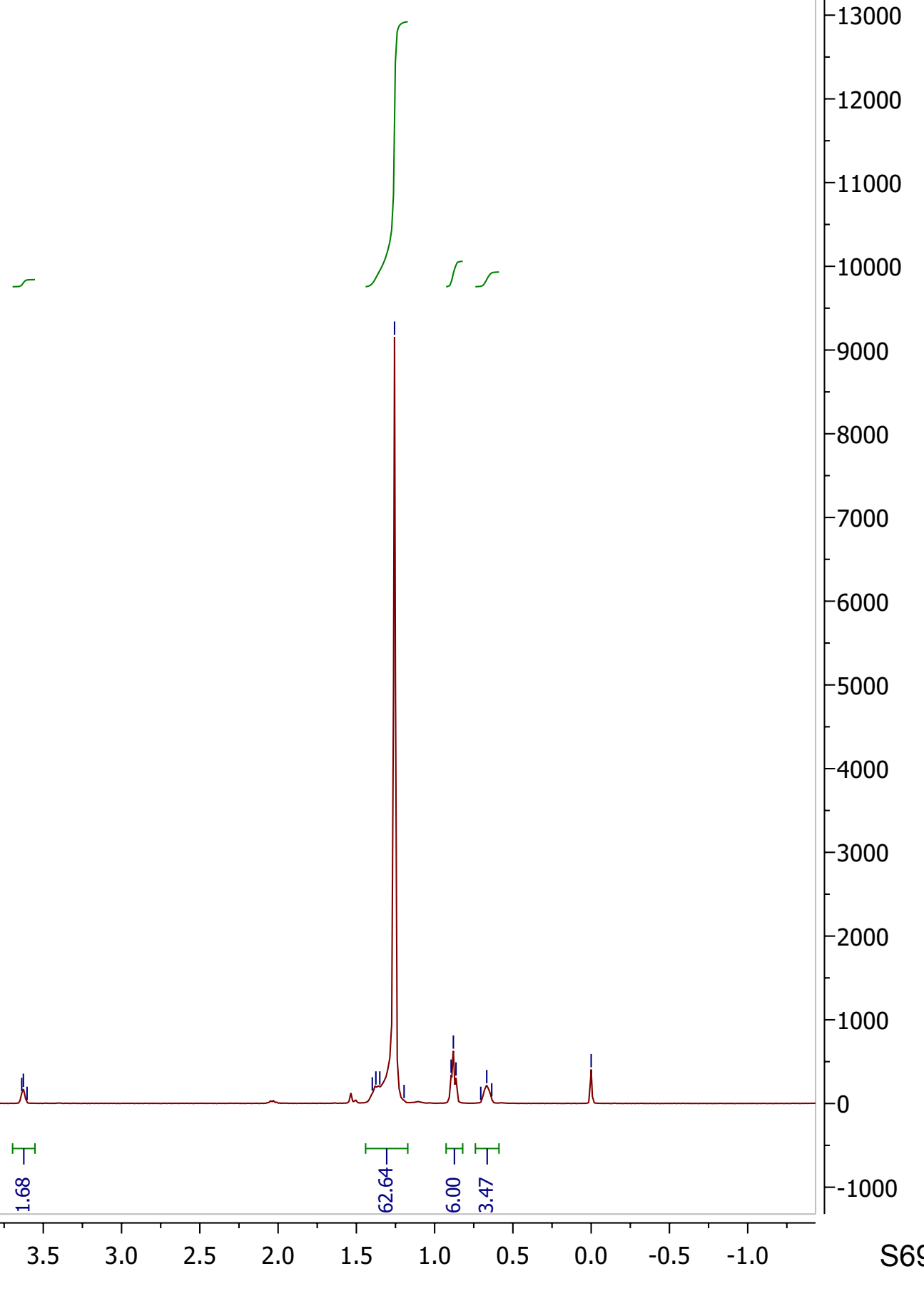


$\left(\mathrm{C}_{18} \mathrm{H}_{37}\right)_{2} \mathrm{SiH}_{2}$

Dioctadecylsilane (6a) 

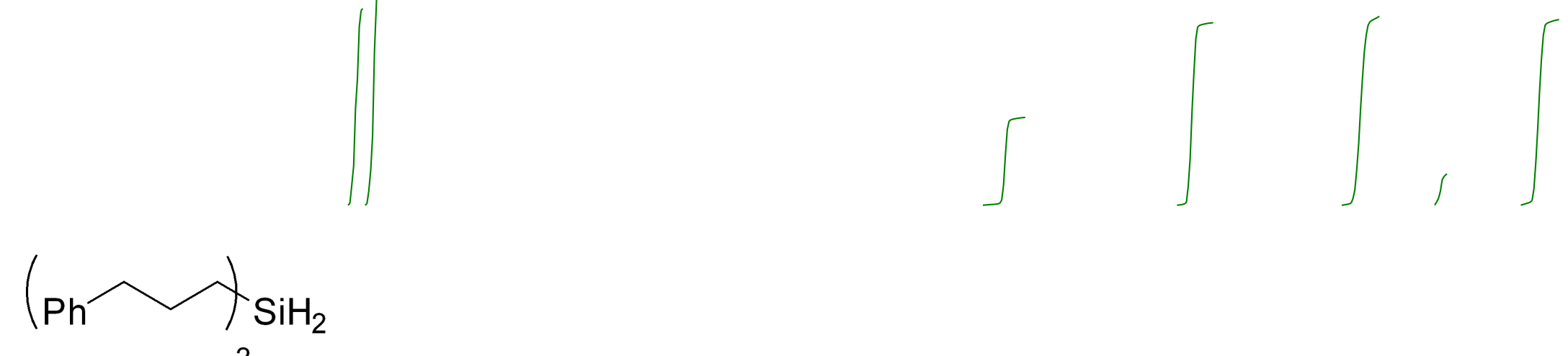

2

Bis(3-phenylpropyl)silane (6b) 


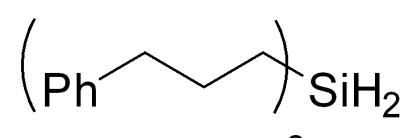

2

Bis(3-phenylpropyl)silane (6b) 
(a)

Bis(2-(cyclohex-3-en-1-yl)ethyl)silane (6c) 


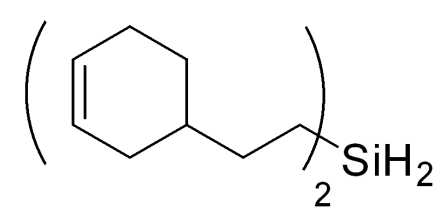

Bis(2-(cyclohex-3-en-1-yl)ethyl)silane (6c) 


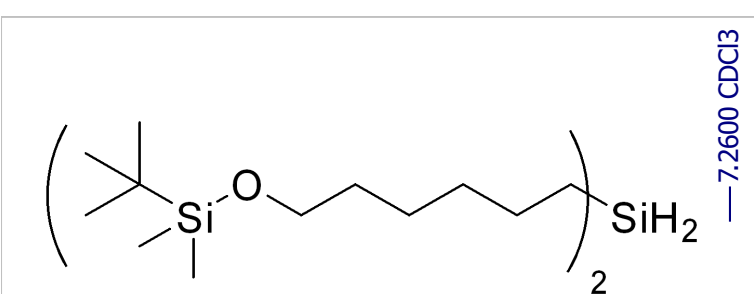

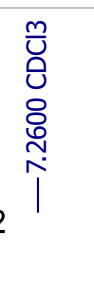

\section{Bis(tert-butyl((6-(dimethylsilyl)hexyl)oxy)silane (6d)}

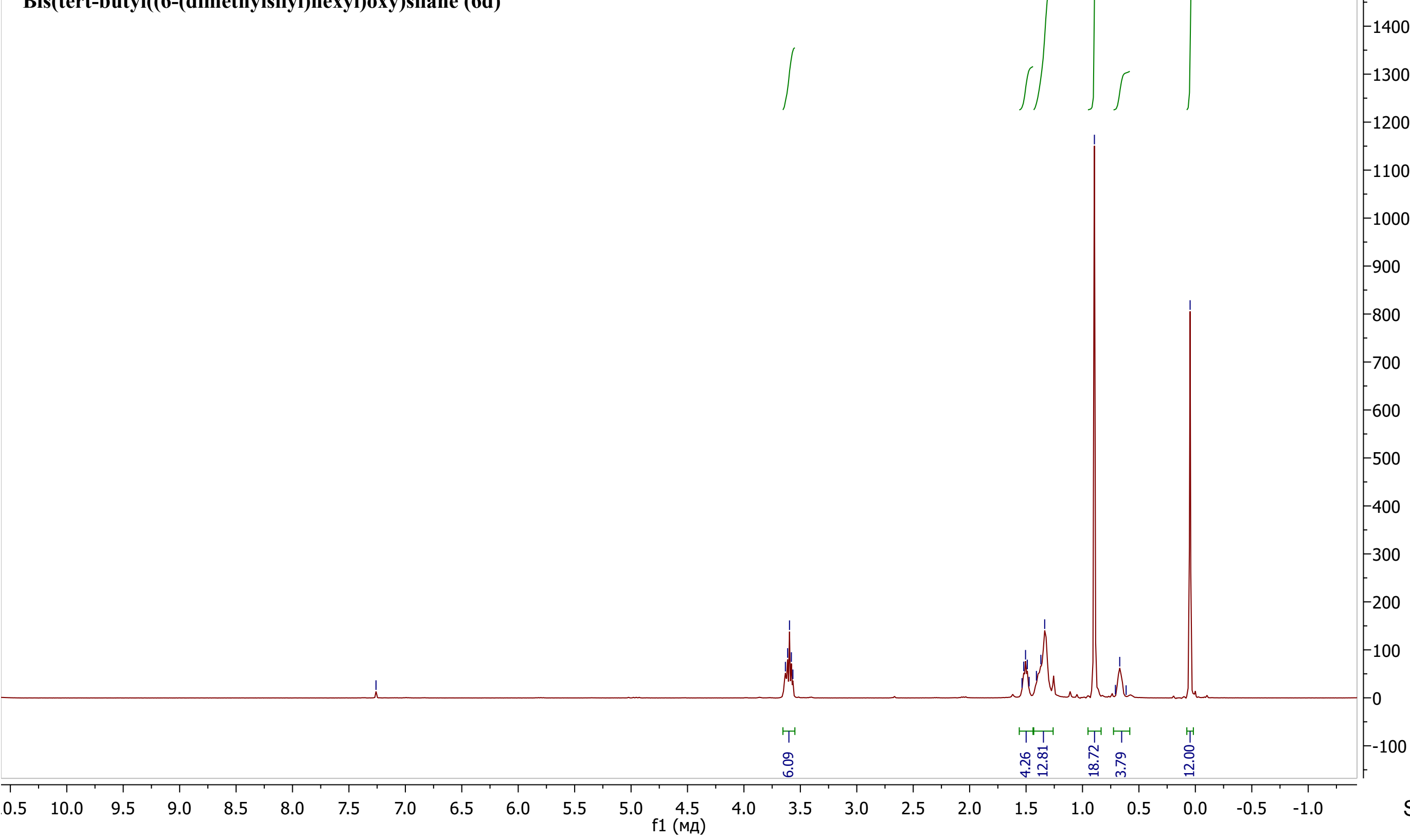




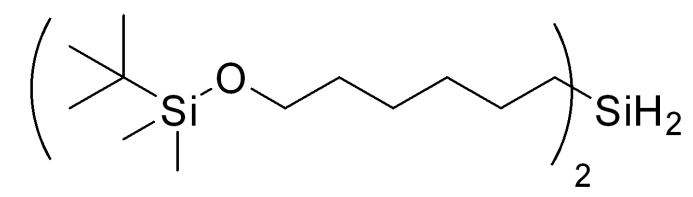

\section{Bis(tert-butyl((6-(dimethylsilyl)hexyl)oxy)silane (6d)}



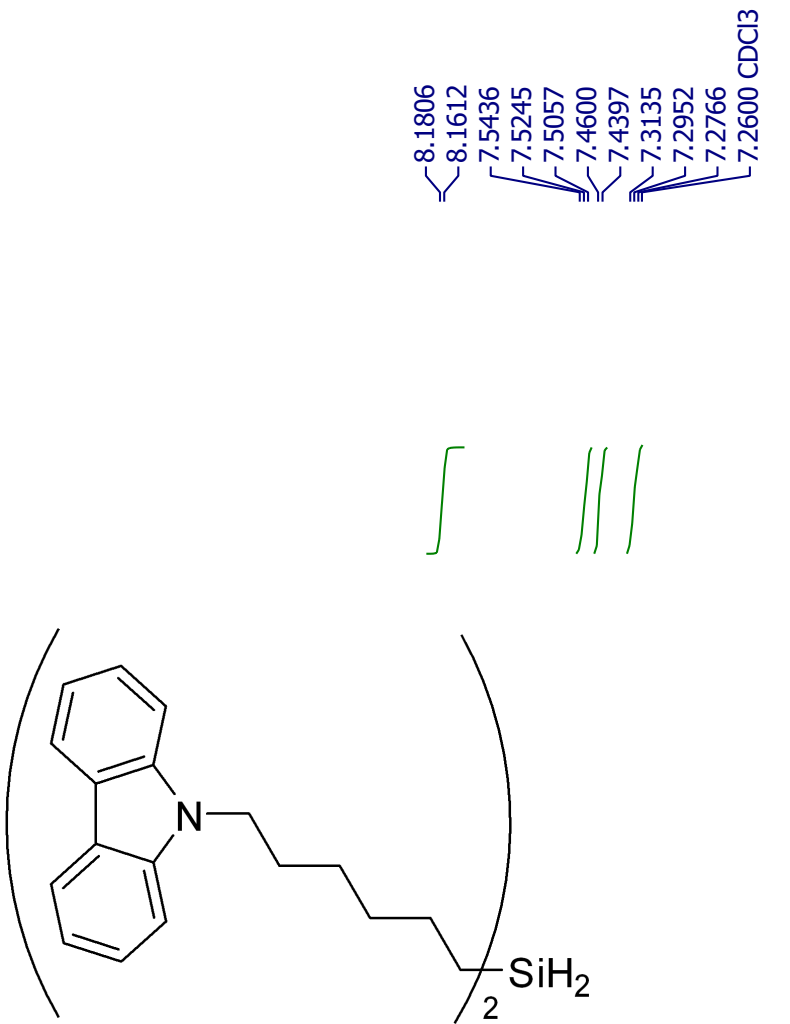

Bis(6-(9H-carbazol-9-yl)hexyl)silane (6e)

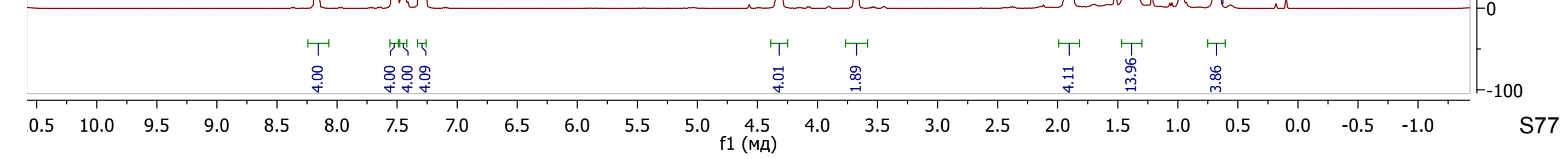




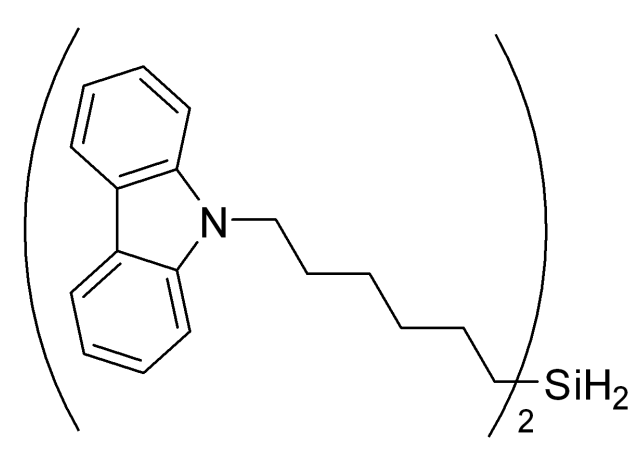

Bis(6-(9H-carbazol-9-yl)hexyl)silane (6e) 


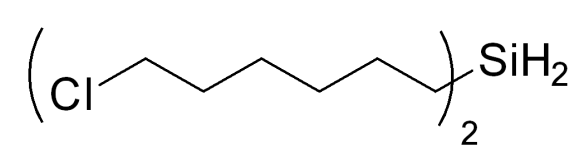

\section{Bis(6-chlorohexyl)silane (6f)}

\begin{tabular}{|c|c|c|c|c|c|c|c|c|c|c|}
\hline 9.0 & 8.5 & 8.0 & 7.5 & 7.0 & 6.5 & 6.0 & 5.5 & 5.0 & $\begin{array}{c}4.5 \\
\text { f1 (Mд) }\end{array}$ & 4.0 \\
\hline
\end{tabular}




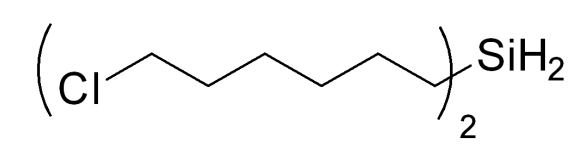

Bis(6-chlorohexyl)silane (6f)$$
\text { Wunw }
$$

$90 \quad 80$
$\mathrm{f1}(\mathrm{Mд})^{8}$

$70 \quad 60$

60

50

40

30

20




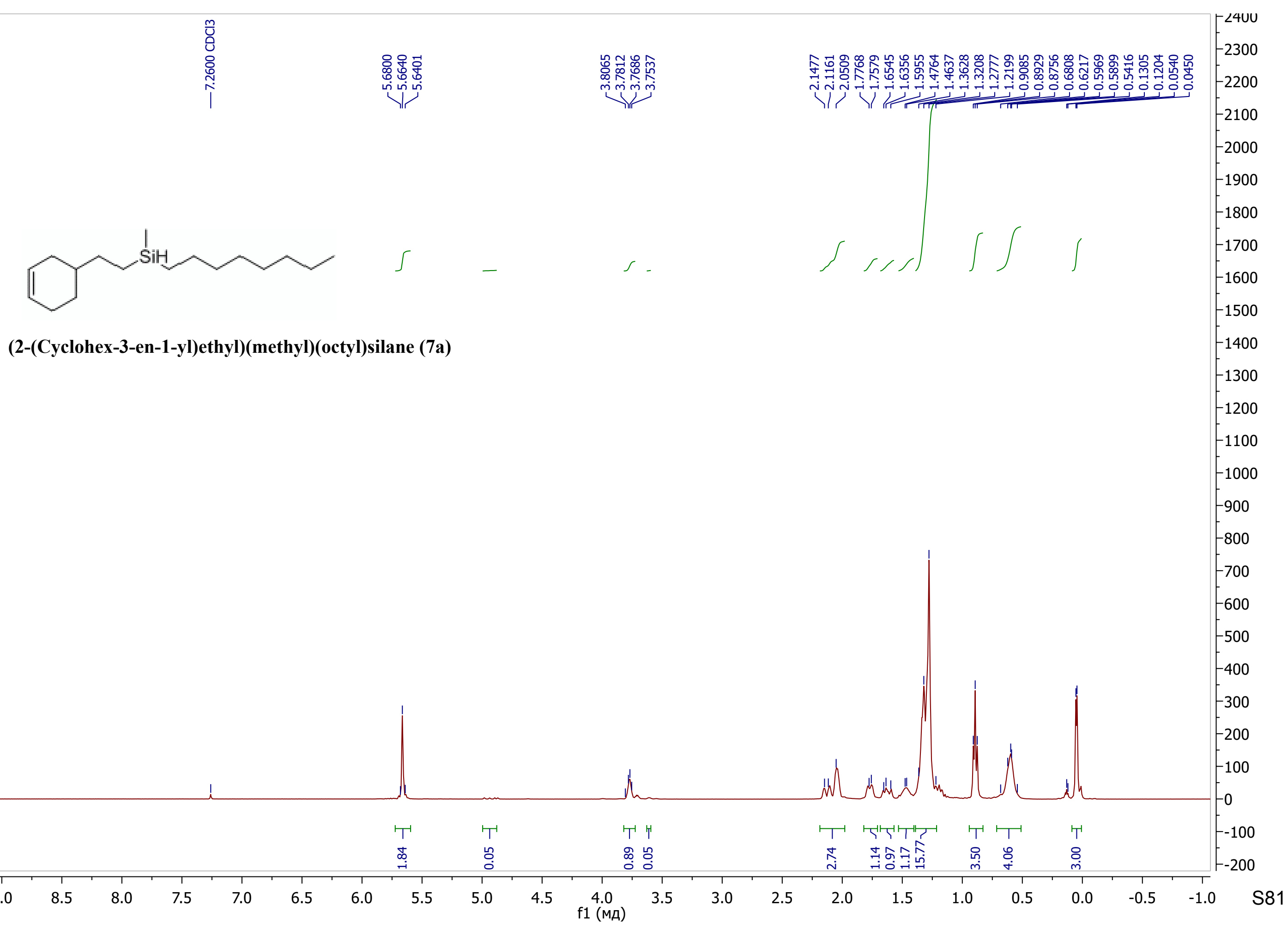




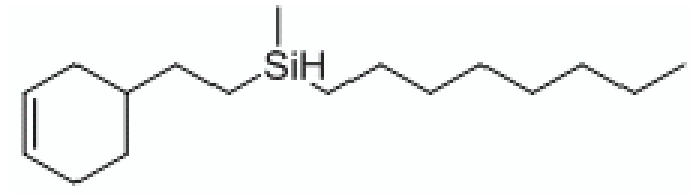

(2-(Cyclohex-3-en-1-yl)ethyl)(methyl)(octyl)silane (7a) 